CuPAUAM 25.1, 1998, pp. 35-70

\title{
ARQUEOMETRÍA Y CONSERVACIÓN DE METALES ANTIGUOS: EL CASO DE LOS HIERROS DE CAPOTE
}

\author{
JoAquín Barrio Martín \\ Fuencisla Hermana MENDIOROZ \\ Departamento de Prehistoria y Arqueología \\ de la Universidad Autónoma de Madrid
}

\section{Resumen}

E] trabajo describe los diferentes aspectos de un estudio de Arqueometría llevado a cabo sobre un grupo de piezas de hierro recuperadas en las excavaciones del yacimiento de El Castrejón de Capote (Higuera Real, Badajoz). Nuestra investigación más importante ha tenido como finalidad efectuar un diagnóstico conrecto del estado de deterioro de los estos objetos, invisibles bajo los productos de corrosión del hieno.

El estudio analítico ha sido posible gracias a algunos fragmentos desprendidos durante el almacenamiento post-excavación, y con la ayuda de las siguientes técnicas experimentales: Radiografia RX, MEB con EDX, DRX y Metalografia. De este modo, con las investigaciones arqueométricas nosotros hemos podido establecer un mal estado de conservación de los útiles de hierro. Se encuentran parcial o tocalmente mineralizados, en un estado de fragilidad; entre orros produços de cortosión el hierro lleva en su interior una proporción elevada de clonjos, elementos éstos inuy agresivos para la conservación y el futuro de las piezas.

\section{Résume}

Le travail décrit les différents aspects d'une étude archémetrique portée sur un groupe de pièces en fer localise dans les fouilles sur le site de Ed Castrejón de Capote (Higuera Real, Badajoz). Notre plus importante recherche a étế de mettre à exécution un diagnostic correct de l'état de détérioration des ces objets, invisibles sous les produits de corrosion du fer.

L'étude analytique a été possible grâce à quelques morceaux détachés pendan le magasinage post-fouilles, à l'aide des suivantes techniques expérimentales: Radiographìe RX, MEB avec EDS, DRX, et Métallographie. Ainsi, avec les recherches archémetriques nous pouvons élablit des conditions de conservation très mauvaises. Ils se trouvent partialement ou complètement minéralisés, en fragile état; entre autres procluits de la corrosion, le fer montre à l'intérieur une haute proportion de chlorures, eléments plus agressifs pour la conservation et futur des pièces. 
En estas líneas introductorias de nuestro artículo, queremos poner de relieve la importancia de la arqueometría para la investigacion de los problemas de conservación y la determinación de propuestas y tratamientos de conservación/restauración adecuados. Así se desprende de las líneas de actuación en los últimos años emanadas del Metal Working Group-ICOM CC, que actualmente reúne al conjunto más amplio de investigadores en este campo (VVAA, 1995; 1998; 2001).

Su utilidad es muy destacable para los restauradores, $、$ la hora de valorar sus resultados en el trabajo de campo o en el laboratorio, al permitir estas herramientas tecnológicas extraer nuevos datos o valorar los disponibles para un diagnóstico objetivo de nuestro Patrimonio Arqueológico Mueble desde una nueva perspectiva, que con el paso de los años se va haciendo más diáfana y enriquecedora (Mourey, 1987, 32-37; Ciliberto/Spoto, 2000). Esto no tiene otro significado que la asunción de la conservación y restauración como una "ciencia moderna", con todos los postulados que se aplican a esta categoría del conocimiento, aunque intrinsecamente arraigada en los estudios de nuestro Patrimonio, y por tanto en las Ciencias Humanas.

En el trabajo concreto que aquí ofrecemos sobre un conjunto de objetos de hierros del yacimiento prerromano de El Castrejón de Capote ${ }^{[3]}$, queremos insertarnos en este ámbito de la ciencia moderna; cuando uno se enfrenta a la tarea de recuperar hasta un estado de conservación aceptable los objetos arqueológicos puede hacerlo desde una perspectiva calificable de "artesanal" o tradicional, como nosotros mismos lo hicimos en nuestros primeros trabajos de restauración de ciertos conjuntos de hierros prerromanos, entre ellos una pieza de Capote (Barrio, 1989; 1994, 303-306), o abordarlo desde unos presupuestos mucho más objetivos y habitualmente conseguidos desde ámbitos más interdisciplinares.

Por otra parte, se puede indicar que la mayoria de las técnicas aplicadas nos vienen desde los campos cientificos experimentales o desde la industria, que ha desarrollado procedimientos de investigación, sistemas aplicados y productos capaces de abordar con mayores garantías el futuro de nuestro Patrimonio Arqueológico. Desde esta perspectiva hemos importado y adaptado un bagaje tecnológico que hoy resulta imprescindible en nuestro trabajo diario, en especial cuando se trata de mejorar las condiciones de conservación de los metales antiguos, cuya intervención y recuperación suele ser compleja y de resultados difíciles, aún contando con el apoyo de la Arqueometría.

Al día de hoy, queremos indicar que la experiencia de trabajo y la analítica son los únicos presupuestos sobre los que se permite avanzar y ofrecer propuestas convincentes y valiosas en el campo de la conservación de materiales tan problemáticos como los objetos de hierro prerromanos, cuyos niveles de deterioro suelen ser muy altos, peligrando su propia entidad física en un espacio de tiempo no muy prolongado.

[1] Este trabajo se enmarca en el Proyecto de la DGICYT ( PB-94/0156) Conservación, Restauración y Tecnología de hierros prerromanos habiéndose financiado por éste zanto los análisis de MEB (SIDI de la UAM), las Radiografias, resultado de la colaboración científica de la UAM con el INTA, en especial con el Sr G. Delojo, como los trabajos de Metalografia, fruto de la relación con el Dpto. de Ciencia de los Materiales e Ingeniería Metalúrgica de la UCM, dirigidos por el Dr. Criado; a ambos nuestra mayor gratitud por su inseres. 


\section{EL YACIMIENTO DE CAPOTE Y LA METALURGIA DEL HIERRO}

El hábitat prerromano de El Castrejón de Capote (Higuera la Real, Badajoz) se encuentra emplazado en el área noroccidental de Sierra Morena, en un paraje rocoso y agreste en los límites extremeños con las sierras onubenses, cercano a Portugal, en un típico espigon defensivo dominante sobre la confluencia del río Sillo y el arroyo Alamo. La geología ofrece formaciones cámbricas con materiales detríticos de bastante potencia. El subsuleo de este poblado está integrado por calizas con módulos pizarrosos. Aunque en el enclave se han descubierto restos calificables de "tartésicos" (estela de guerreros), las excavaciones prolongadas durante los primeros años noventa bajo la dirección del Prof. Berrocal ${ }^{[2]}$ han sacado a la luz un poblado habitado entre los siglos V y I a.C., en el destaca no sólo su arquitectura defensiva sino una trama urbana bien articulada en el eje de una calle principal, con viviendas de planta cuadrangular y varias estancias construidas con piedra del lugar.

Se pueden distinguir tres fases de ocupación:

- Nivel de ocupación 4 (finales del V a. C.), un asentamiento inicial con escasa conservación estratigráfica, pero ya con defensas y un incipiente urbanismo.

- Nivel de ocupación 3 (entrado el IV al II a.C.), con un gran desarrollo de las estructuras defensivas y de habitación, entre cuyas estancias centrales destaca en la calle principal el denominado "Altar", un espacio sacrificial abierto rodeado de estancias con depósitos votivos de notable singularidad.

- Nivel de ocupación 2 (finales del siglo II a.C.), donde se reutilizan las estructuras y los diseños urbanos, que se abandonan súbitamente dejando las habitaciones y las calles repletas de materiales (Berrocal,1994, 19-46).

A esta última fase del yacimiento corresponden la mayor parte de los objetos de hierro que forman la muestra de nuestra investigación, integrantes a su vez de un registro muy abundante de piezas de este metal que llega a superar el millar. A la luz de los datos que ofrecen los análisis tipológicos de éstos productos manufacturados y de los restos de escorias muy bien puede afirmarse que en el poblado de Capote existía no sólo un taller de herrero sino hornos para la reducción de mineral transformándolo en hierro metálico (Berrocal, 1992, 177-179; Gómez Ramos, 1995, 679-689).

En cuanto a la ubicación de los elementos de la muestra, el número mayor de objetos de nuestro listado se localizó en el sector Este (Fig. 1), concretamente en la estancia HE$C$, aunque también en la GE-I (martillo tajadera); sólo en algún caso se recuperan en zonas de calles o espacios abiertos, como un cuchillo afalcatado y una hoz (VE-A y WE-A, respectivamente). De ello se deriva que el grupo principal estuvo sometido a unas condiciones ambientales en el interior de la tierra muy similares, al menos en hipótesis, pues no dis-

[2] Agradecemos sinceramente al Dr. Berrocal el sernos prestadas todas estas piezas para su estudio analítico y restauración. 


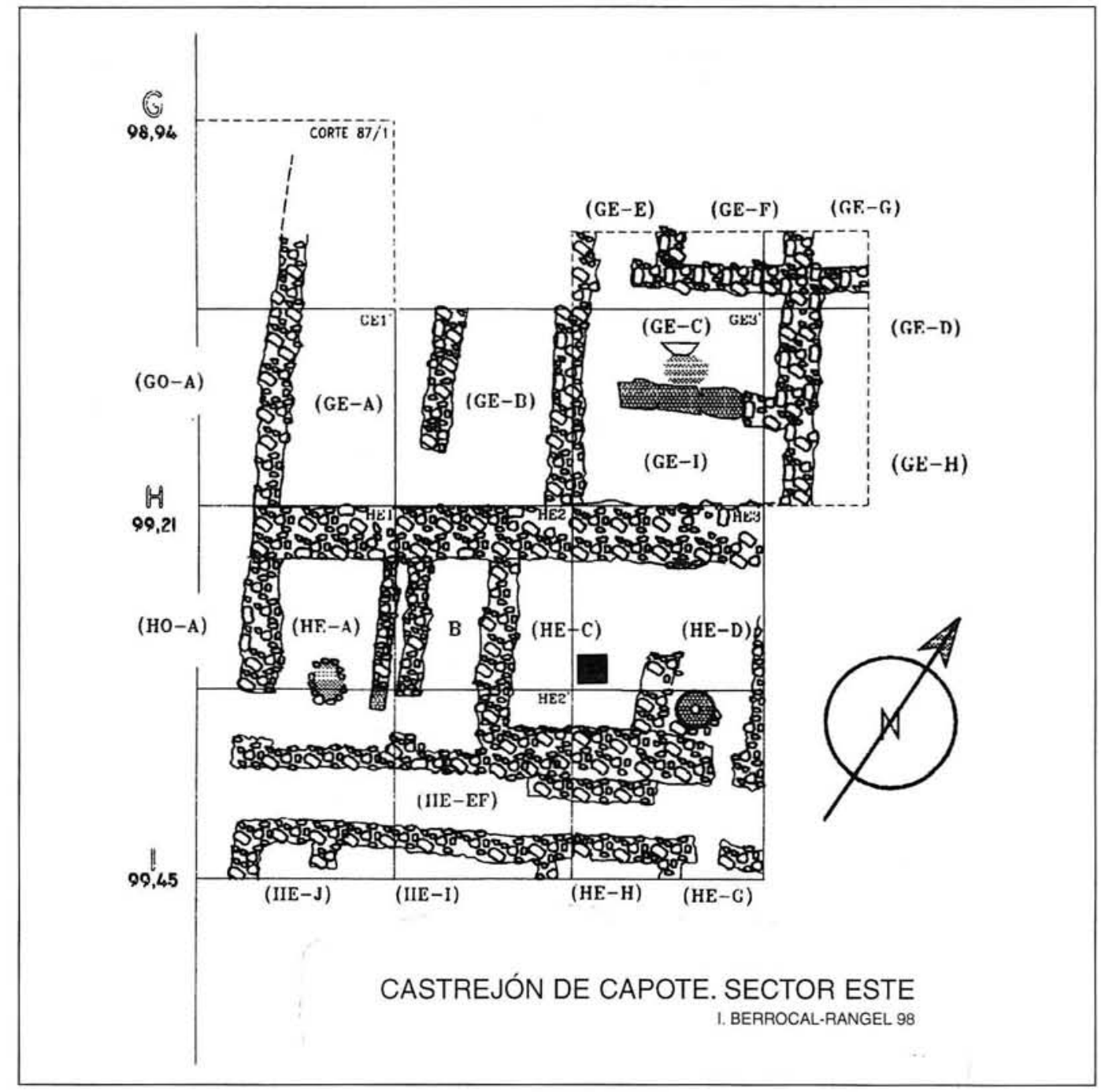

Fig.1. Planimetría parcial del hábitat de El Castrejón de Capote, con indicación de la estancia donde se localizó el grueso de las piezas.

ponemos de muestras de estas tierras, ya que en el momento de la excavación no se planteó por parte de los investigadores llevar a cabo un estudio tan minucioso de los problemas de deterioro de los hierros que se iban extrayendo. La incidencia concreta de estas variables (HR, T, pH, sales, porosidad, compacidad,...) es la causante, sin duda, del estado de conservación tan lamentable en que nos han llegado muchas de estas piezas (Royuela, 1991; Angelini et al., 1998; Wagner et al., 1998). Es lógico pensar que la pudrición de los materiales orgánicos procedentes del derrumbe de las techumbres, entre las que quedaron 
sepultados los materiales de hierro, generara dentro de las estancias unas condiciones de mayor acidez que en el exterior de las viviendas, propiciando una corrosión más elevada. Algunos trabajos bien recientes sobre piezas de hierro romanas de La Olmeda, apuntan a un interés creciente por este tipo de análisis de las condiciones geologicas de los suelos de deposición (Gómez de Salazar/ Soria, 2000, 203-205). Bien es verdad que la tecnología de manufactura de los hierros y su uso pueden determinar también la resistencia mayor o menor de los objetos a la corrosión, pero este es un valor que las investigaciones aún no han precisado con detalle, aunque todos los que trabajamos en este campo no dudamos que es así.

Desde el punto de vista tipológico y tecnológico, los objetos de que disponemos del Castrejón de Capote (Berrocal, 1992, 148-162; 1994, 235-243), nos presentan la metalurgia de la etapa prerromana más inmediata en un momento de su máxima evolución, plenamente comparable a los registros de las áreas ibéricas (Plá Ballester, 1968; Sanahúja, 1971, 61-110) y celtibéricas. (Barril 1992, 5-20; Jimeno et al 1999, 103-113; Lorrio et al. 1999, 161180).

De todo el largo listado que conforman estos materiales de hierro recuperados en las excavaciones del yacimiento de La Beturia Céltica del Castrejón de Capote, las piezas proporcionadas y seleccionadas, un conjunto suficiente y representativo de la tecnología y del utillaje que se da en este hábitat prerromano extremeño, son éstas:

- Cuchillo afalcatado 1 (completo).

- Cuchillo afalcatado 2 (fragmentado incompleto).

- Hoz 1 (fragmentada incompleta).

- Hoz 2 (completa).

- Punzón.

- Vástago curvo.

- Clavos grandes (2).

- Martillo tajadera (aparece como "pico").

- Pesa con orificio central.

\section{ANÁLISIS RADIOGRÁFICO}

A la hora de abordar cualquier estudio del estado de conservación de metales arqueológicos, resulta de una excepcional utilidad en este campo el análisis Radiográfico, puesto que muchas de las piezas llegan desde la excavación en condiciones poco reconocibles. Se trata del primer tipo de investigación analítica que podemos hacer con nuestros objetos al llegar al Laboratorio. Aunque es susceptible de aplicarse sobre materiales arqueológicos muy diversos son especialmente las colecciones metálicas las que requieren una mayor ayuda de esta técnica (Gilardoni, 1994; Antelo/Gabaldón, 1997). 
Además, en función de las características que tienen estos hallazgos de objetos de hierro recuperados en "medio tierra", con buena parte del aglomerado geológico que les rodeaban, la Radiografía se convierte en una técnica de trabajo inicial de una gran valía para la tarea posterior de la restauración y conservación de estas piezas (Barrio et al., 1999, 239-247). Queremos poner de relieve que su carácter de análisis no destructivo (END), y sin limitación de condiciones de trabajo o de volumen y peso del objeto, la convierten en una técnica especialmente útil, aunque su descubrimiento date ya de más de un siglo. Tíne notable relevancia esta característica de técnica "no destructiva", pues es el campo del Patrimonio, y muy especialmente en la conservación o restauración de éste, priman cada vez más las técnicas que no precisan muestra o que ésta apenas tenga pérdida durante el proceso de diagnosis. En un futuro inmediato los análisis ecogräficos o ultrasónicos, bien desarrollados ya para la industria, serân habituales en el diagnóstico de estos problemas de deterioro, aunque estas técnicas END deberân ser puesta a punto para casos tan singulares como los que ofrece la investigación del Patrimonio (Ramirez/Delojo, 1999).

Así pues la Radiografía convencional permite una comprobación eficaz de la situación de la estructura interna de un objeto, en numerosas ocasiones cubierto por una gruesa capa de concreciones o alteraciones deformantes que impiden observar los rasgos de su superficie, y por supuesto, la situación interna de la pieza, en especial si ésta no se encuentra fragmentada. Los rasgos que la radiografia nos muestra son relativos a decoraciones subyacentes, estado del núcleo metálico y proceso mineralizador, fisuras y microfisuras, reparaciones antiguas, etc.... En este sentido la utilidad de las placas RX han sido imprescindibles para la localización de damasquinados de plata sobre piezas de hierro prerromanas, al permanecer invisibles bajo la corrosión deformante (Prats et al., 1996: 137-142).

Es preciso poner de relieve que la realidad nos ofrece una mayoría de éstos objetos en un estado de conservación tan deficiente a su llegada desde la excavación que dificulta el análisis de las características formales, decorativas o de tecnología constructiva de los dichos materiales. Por desgracia para nosotros este es el panorama habitual de los objetos que presentamos en nuestro trabajo procedentes de Capote, incluso para los que a posteriori aparecerán como mejor conservados.

Existen razones de peso a la hora de evaluar los beneficios de los análisis radiográficos. Quizás el objetivo más relevante esté en saber con la mayor precisión el estado general del núcleo metálico y por tanto de la compacidad de la estructura de la pieza. La determinación de la solidez del núcleo de hierro es vital para decidir la aplicación de un sistema de conservación determinado, sobre todo de una técnica de limpieza adecuada a sus condiciones de resistencia. La aplicación de una relativa presión mecánica sobre la estructura del objeto, teniendo en cuenta que el grueso de los productos de corrosión del hierro suelen ofrecer una notable resistencia a la limpieza manual, se ha de realizar sabiendo de antemano la capacidad de retención. Si se desconoce esta propiedad, relacionada directamente con la existencia de un núcleo metálico sólido y la ausencia de fisuras profundas, las presiones a las que se someten durante la intervención restauradora podnían acabar fragmentado aún más el objeto. El conocimiento aportado por una radiografia es imprescindible para abordar el trabajo con garantías, y evitar problemas muy graves e irreversibles. Así lo hemos constatado en todos los casos que presentamos, algunos de los cuales mostraban 
un hierro profundamente mineralizado, sólo con residuos en puntos muy concretos, caso por ejemplo la Hoz 1 o del Cuchillo 2.

Es así mismo necesario la detección de la presencia de fracturas que fragmenten la pieza, e incluso de fisuras o microfisuras de un menor calado, pero que a la postre pueden determinar la intergidad de ésta, y que resulta a todas luces imprescindible conocerlo previamente. Y más si la pieza ya se encuentra con un núcleo muy degradado. En muchas de las metalografias presentadas de algunas piezas de Capote se ha detectado la existencia de numerosas microfisuras en las capas fibrosas de magnetita o hematita. Este reconocimiento puntual metalográfico puede extenderse a toda la pieza y no sólo a la muestra metalográfica si realizamos una placa de $\mathrm{RX}$.

Resulta, así mismo, obligado el reconocimiento de la característica morfológico de la corrosión; si ésta es mediante picado, lineal o laminar, ... Estos son rasgos difíciles de observar en superficie, pues las capas de mineralización más externas suelen ocultar áreas de corrosión en profundidad no detectables.

Así mismo, en los últimos años ha tomado cierta prevalencia para los restauradores de hierros antiguos la localización de la superficie original de las piezas de hierro (Bertholon/ Relier, 1992, 185-190; Bertholon, 2001). Va muy vinculado a los problemas estructurales antes mencionados, y tiene una gran importancia si queremos conservar piezas de hierro que no sólo sean un objeto deforme e irregular, una simple "raspa" de lo que fueron. La recuperación de estas películas originales durante el proceso de limpieza es uno de procedimientos más complejos y a la vez de mayor interés para la conservación de estas piezas prerromanas (Prats, 1998; Alonso et al. 1999, 133-147).

$\mathrm{El}$ análisis de los elementos y marcadores que puedan identificar la superficie original transformada ya en compuestos minerales del hierro en piezas sometidas a sucesivos tratamientos tếrmico-mecánicos durante su manufactura, es un problema que puede ser abordado en el estudio radiográfico, pues no existe un único compuesto mineral que se pueda identificar como propio de las películas superficiales de estos hierros antiguos. No obstante hay que decir que en muchos casos es la Magnetita la presenta una más acertada identificación como tal, p.e. en las armas de La Hoya (Alonso et al., 1999: 124-132). Recientemente en un análisis de Microdjfracción de RX de una falcata de El Salobral comprobamos la escasa diferencia entre el núcleo mineralizado al completo y la película exterior; el paquete de compuesto era casi idéntico, y en él no estaba presente la Magnetita (Barrio/ Hermana, 1998).

Una película original habitualmente cubierta por abundantes productos de corrosión y, lo que es más problemático, desplazada en altura de su posición por una corrosión subyacente. Esta posición encorsetada entre la capa de corrosión externa y el núcleo convertido en mineral, así como la escasa o nula diferencia compositiva con la formación corrosiva de ambas capas dificulta su localización, resultando ser la Radiografía la mejor ayuda para determinar la situación exacta de dicha película. Bien es verdad que se están desarrollando aplicaciones de sistemas ecográficos que pueden dar resultados en los próximos años (Ouahman et al., 1998, 173-174). 
Como venimos comprobando por nuestras experiencias en restauración de hierros de esta época prerromana, la recuperación de la película original de estas piezas, a la que no queremos calificar de "pátina" (salvo la Magnetita en lámina regular), pues carece de la belleza y homogeneidad de la formada en los bronces, siempre resulta nuy dificultosa, siendo una precisa combinación de los tratamientos de limpieza manuales con el apoyo puntual de limpieza química o electroquímica, la que parece ofrecer un mejor resultado. De todos modos, los criterios formulados en la última Carta del Restauro de Roma de 1987 se decantan hacia el uso mayoritario de limpiezas mecánicas, simples y controlables en cada momento. Lo que en otro tiempo fue habitual, las limpiezas electroquímicas generales, hoy son ampliamente descartadas, pues con ellas se perdería todo rastro de la superficie original de los objetos férreos.

En esta complicada actividad de detección de superficies, la Radiografia ha resultado ser una guía imprescindible para el buen fin de la conservación y restauración de las piezas de hierro, y mucho más para objetos con alta degradación como suele ocurrir con buena parte de los investigados de Capote.

En el momento de realizar los análisis radiológicos, la principal característica que hemos de tener en cuenta es que la masa de productos de la corrosión de estos hierros forjados ( 6 xidos, hidróxidos, carbonatos, tierras y materia orgánica,..) son materiales que, además de su escasa compacidad, absorben la radiación bastante menos que el hierro metálico. Por eso en las piezas de este conjunto se pueden observar zonas de alta absorción radiográfica que se evidencia en zonas más claras, con menor nivel de grises (núcleo metálico restante), y también muy abundantes zonas de baja absorción que dejan su rastro en áreas más obscuras, de alto nivel de grises (paquete de productos de deterioro y estructuras mineralizadas). En este último caso se correspondería con las capas de corrosión que necesitan unas condiciones radiográficas de menor energía, y por ello su visualización se vuelve más difícil.

Interesa, por lo demás, detallar las condiciones radiográficas para el análisis de las piezas de Capote; éstas son las que siguen:

Agente radiográfico

Tensión

Exposición

Filtros

Hojas reforzadas

Película

Distancia f.p.
Rayos X

80 a $120 \mathrm{kV}$ (general),

$250 \mathrm{kV}$ martillo tajadera y pesa.

$9 \mathrm{~mA} \times \mathrm{min}$

En ventana: $1 \mathrm{~mm} \mathrm{Al}+3 \mathrm{~mm} \mathrm{Be}$

En película. $0,3 \mathrm{~mm} \mathrm{Cu}$.

$0,02 \mathrm{~mm} \mathrm{~Pb}$ entre 100 y $120 \mathrm{kV}$

Tipo II/ ASTM

$700 \mathrm{~mm}$ 
Teniendo en cuenta los objetivos planteaclos en las líneas precedentes, los análisis radiográficos sobre las piezas de Capote nos permiten las consideraciones de interés que siguen.

La placa de la $\mathrm{Hoz} 1$, (Fig.2) que se presenta en varios fragmentos, muestra una escasa presencia de núcleo metálico, quizás sólo residual en puntos inconexos, más próximos siempre a la parte superior de la lámina, cerca de la zona del enmangue; sin duda el mayor espesor lo ha hecho posible. En el dorso superior se aprecia la línea continua de la superficie original, levemente desprendida de su situación. La mineralización diseña un mapa irregular de áreas con distinto grado de pérdida de materia metálica, situación que parece haber llegado en su desarrollo completo en todo el filo y los fragmentos de menor tamano. No se destacan fisuras apreciables, que hagan pensar en nuevas fracturas.

En cuanto a la $\mathrm{Hoz} 2$ su análisis radiográfico permite alguna puntualización más (Fig.3 ). Es muy destacable las notables diferencias de mineralización entre la zona de corte de la hoz y el sector del enmangue, donde queda aún parte de su núcleo metálico, aunque se presentan puntos ya perdidos; es de destacar la perfecta definición de los dos remaches del mango, uno de ellos ya inexistente y el otro que ha mantenido el hierro casi intacto. El proceso de mineralización ha llevado a la desaparición de la región intermedia, donde la unión es endeble y sin fibra en estado metálico que la sustente. Por lo que respecta a la zona extrema de la hoja se muestran con claridad los focos de corrosión completa en forma de cráteres, típicos de la actividad permanente y activa. Sólo en la zona intermedia del dorso de la hoz se ve un pequeño rastro de la película original separada ya por una pequeña fisura longitudinal, lógica en el fenómeno de hojaldrado del hierro de estas piezas realizadas a forja.

En el Cucbillo 1, la impresión de la placa nos permite algunos aspectos a valorar (Fig.4). Por un lado la diferencia del estado del hierro entre la virola de la empuñadura, bien conservada, y el resto de la hoja, cada vez mineralizada en mayor medida según nos acercamos a la punta, si bien no llega a los niveles de la pieza anterior. Resaltan de nuevo los cráteres en forma de picadura activa donde la corrosión es muy alta, así como en los tres remaches del mango, ya sin residuos de iones metálicos de hierro. En esta pieza sí podemos ver bien recortada la línea de la película original en el dorso de la hoja del cuchillo, y algo menor en el filo; no obstante se pueden apreciar algunas fisuras que lo desplazan en altura.

Unas caracteristicas generales muy parecidas nos ofrece la radiografía del Cucbillo 2, también con la virola reteniendo un núcleo metálico mayor, así como en el remache detectado (Fig. 5). El resto de la hoja, en varios trozos, tiene una elevada mineralización, sólo con alguna área de residuos metálicos aislados que suelen tener poca importancia para la resistencia mecánica del objeto. Ha perdido tanta materia que no quedan restos de la superficie original del cuchillo. En este caso se pueden destacar con claridad las fisuras profundas, a punto de separar el fragmento de hoja del mango; la línea que se marca en éste a partir del remache es de menor entidad. El hecho es un buen ejemplo de como se desarrolla este proceso de fragmentación en una pieza como ésta, hasta concluir en una gran descohesión, que supone la rotura y separación completa de una parte de ella. 

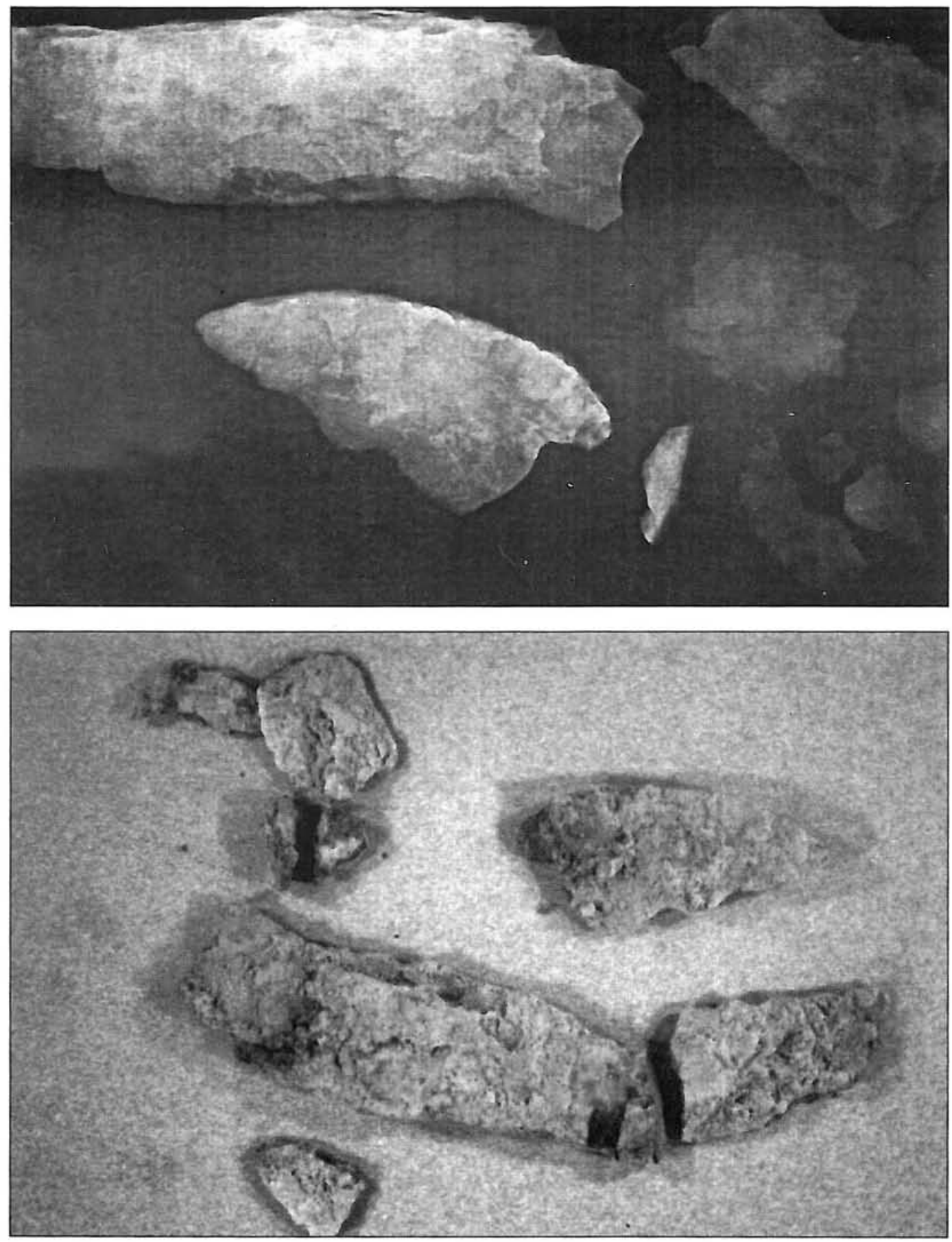

Fig. 2. Hoz 1. Placa RX de la pieza y situación inicial. 

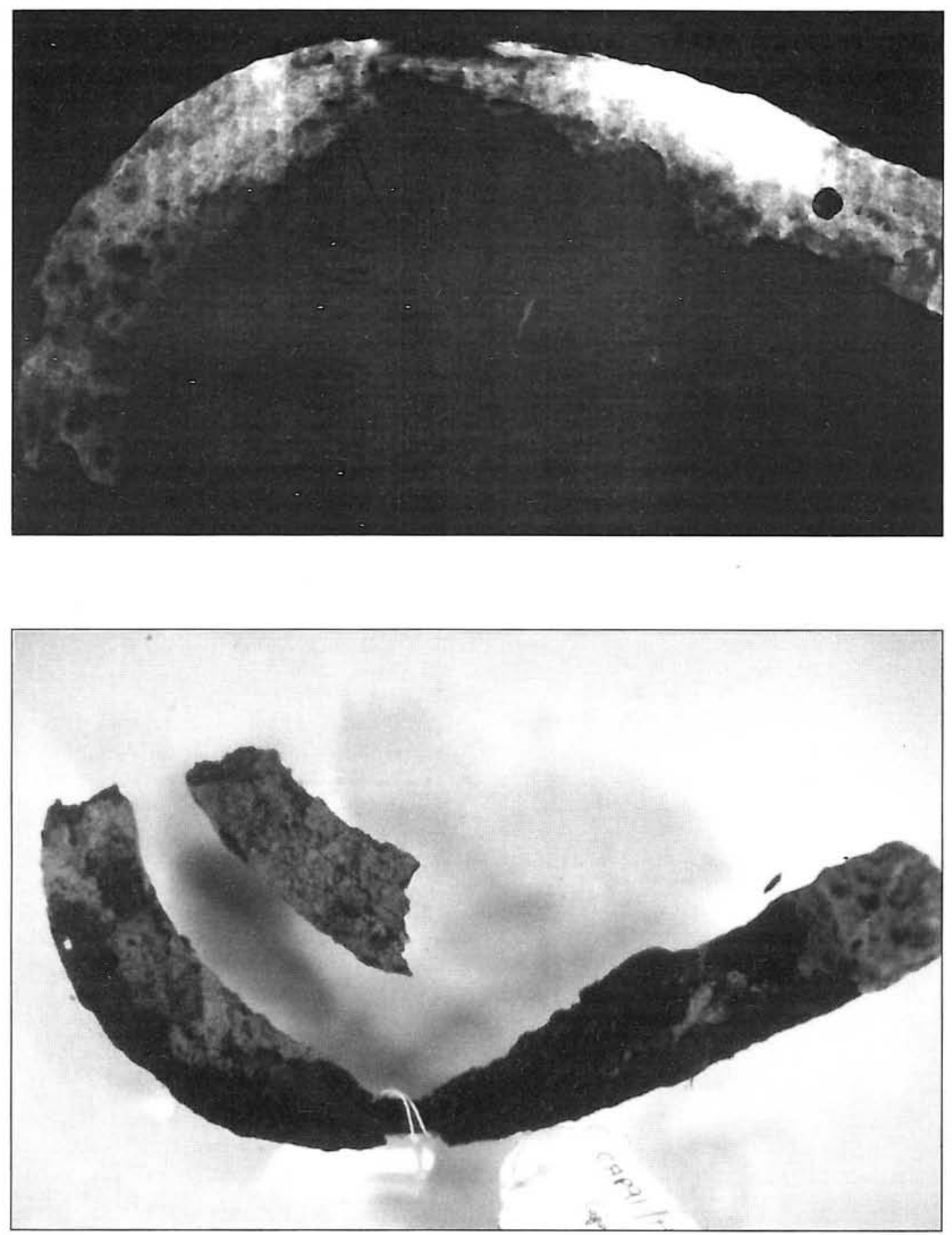

Fig.3. Hoz 2. Placa Radiográfica y estado inicial. 

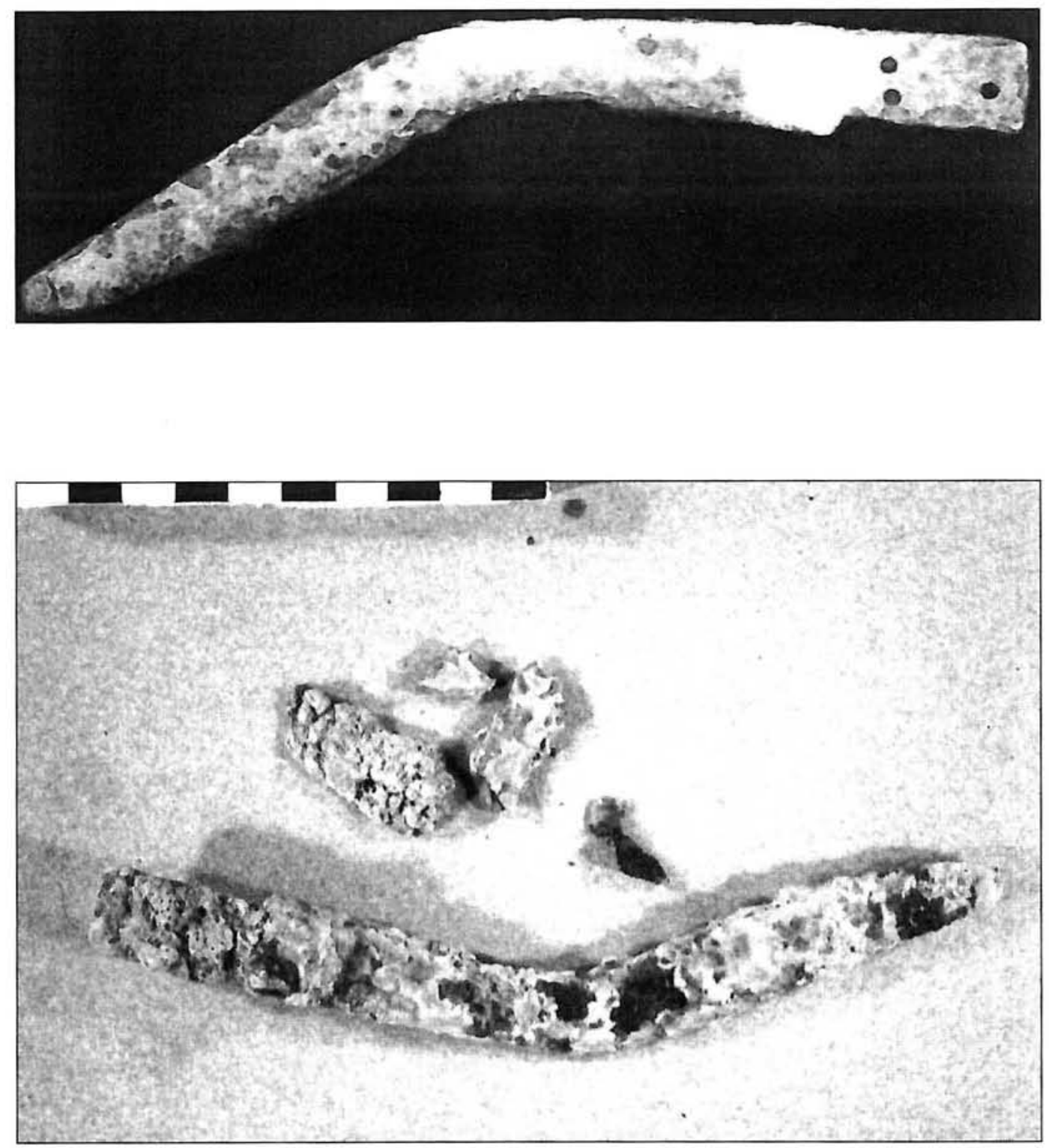

Fig.4. Cucbillo 1. Placa Radiográfica y estado inicial. 

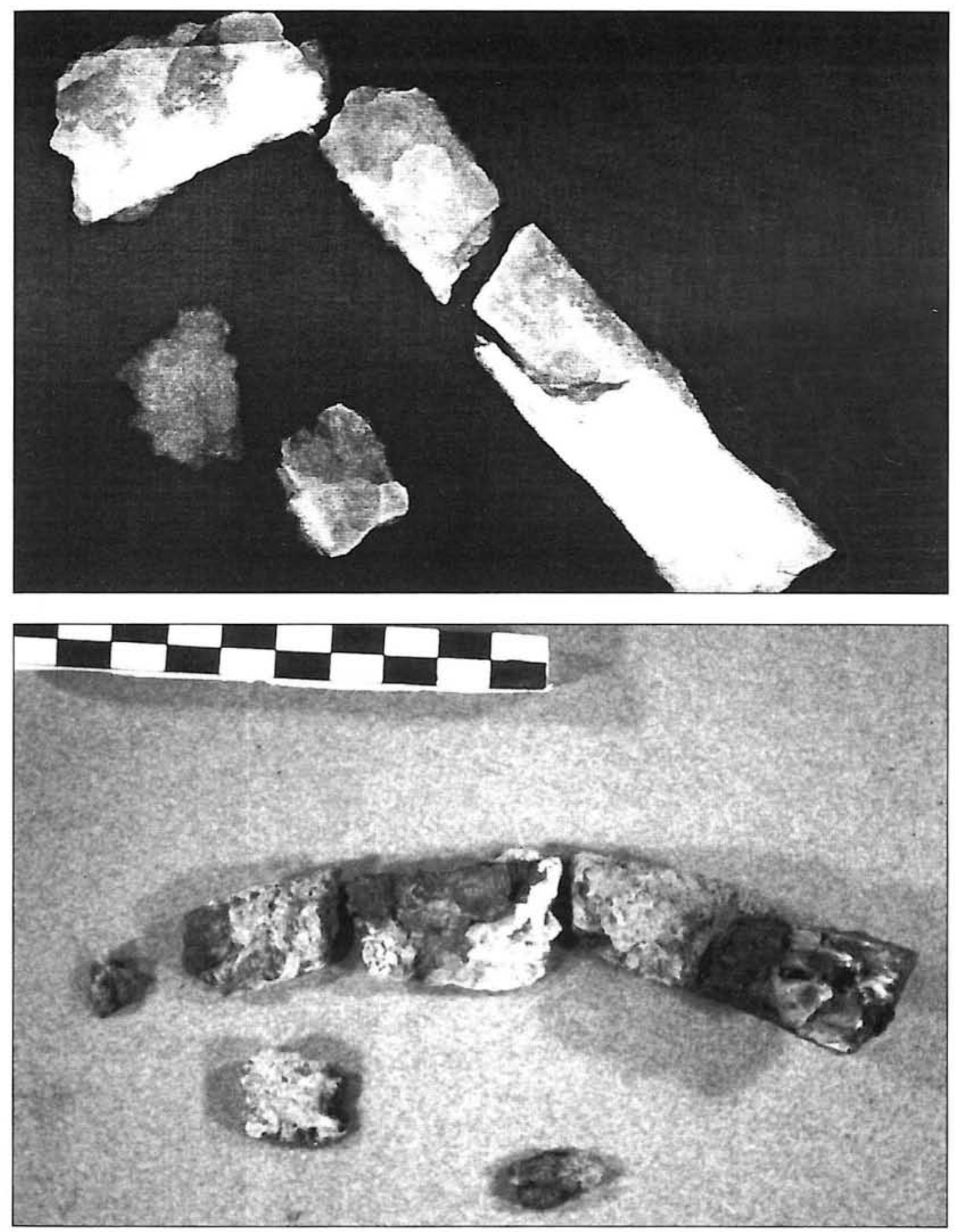

Fig. 5. Cuchillo 2. Placa Radiográfica y estado inicial. 
En cambio en el Punzón la radiografía nos mostraba, al contrario, de existencia de numerosas fisuras longitudinales que prolongan su inserción hasta la zona del extremo, no obstante conserva un núcleo metálico muy sólido salvo en la punta. En ésta el tratamiento mecánico continuo de la forja ha provocado una mayor vulnerabilidad de la estructura del hierro a la corrosión, detectable en el hojaldrado más que en la forma de cráteres activos como vimos en piezas ejecutadas en hoja plana.

Referente a los Clavos, en ambos casos ofrecen algunos rasgos muy similares a los del punzón, con un núcleo metálico muy consistente en la zona de la cabeza y una manifiesta mineralización a partir de la mitad, llegando a perder los iones metálicos en la punta (Fig. 6). De nuevo se observan fisuras longitudinales que magnifican las tensiones interiores de los productos de corrosión en su aumento de volumen y en especial la presión de los cristales de éstos. Queremos resaltar en el clavo fragmentado el excelente reconocimiento de la película exterior, desplazada ya de su posición por la alteración corrosiva.

En último lugar resulta útil valorar las radiografías de las dos piezas en mejor estado, el martillo tajadera y la pesa; en ambas es nanifiesto el excelente y homogéneo núcleo metálico, donde no se observa ningún tipo de picadura o grieta. Los perfiles de la superficie original son nítidos y continuos, sin que se observen capas desprendidas como en muchas de las piezas anteriores (Fig.7). Puede destacarse también el claro reconocimiento de otro metal que rellena los contomos del orificio de la pesa. Sólo el pico del martillo muestra una menor intensidad en el núcleo, aunque es posible que se deba al menor espesor en relación a la totalidad de la pieza. El ojo para el mango, completamente relleno de tierras en el momento de realizar la placa de RX, no evidencia los restos de ninguna espiga o pasador de sujección.

\section{ESTUDIO METALOGRAFICO}

Por nuestra parte, los análisis de arqueometalurgia (Criado et al., 1998, 12-ss), han sido realizados a partir de pequeñas metalografias sobre muestras terminales o de zonas de fractura, después reintegradas al objeto en la fase de restauración. Su estudio nos ha permitido tener una idea de las características técnicas de la siderurgia de Capote, hasta este momento sólo conocida por algunos análisis de escorias, pero no de útiles. Así mismo, hemos de resaltar el valor de estos procesos de manufactura para poder establecer los problemas de deterioro derivados de ìa corrosión, y si éstos tienen que ver con la tecnología.

El protocolo de trabajo para este estudio e identificación analítica ha llevado aparejado el uso de las siguientes técnicas:

- Microscopía óptica.

- Microscopia Electrónica de Barrido con EDX.

- Difracción de Rayos X.

Como hemos puesto de relieve en otras ocasiones (Bartio, 1997,119) los tradicionales análisis metalográficos pueden ser útiles para averiguar también problemas de deterio- 

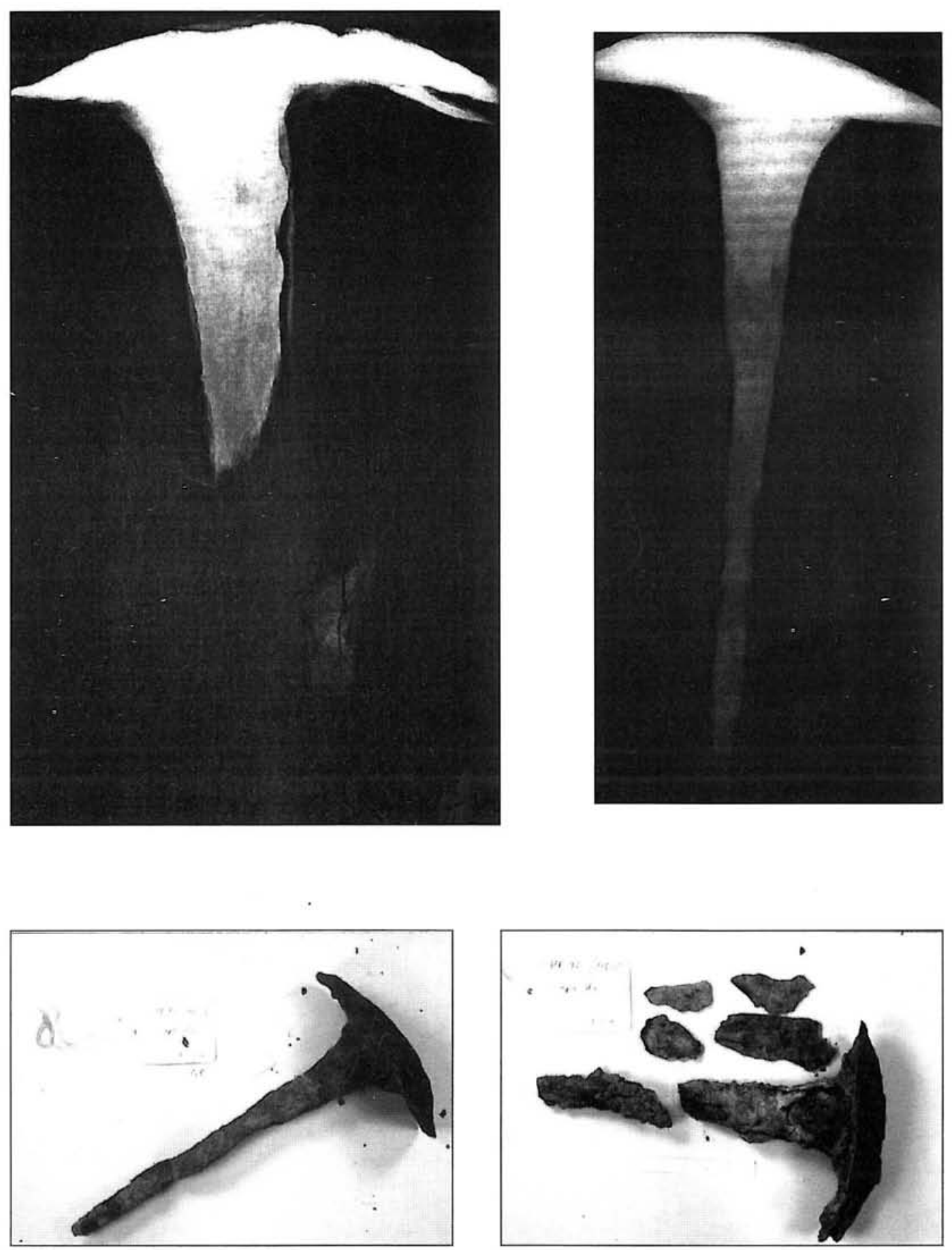

Fig. 6. Clavos. Placas RX de las piezas y situación inicial. 

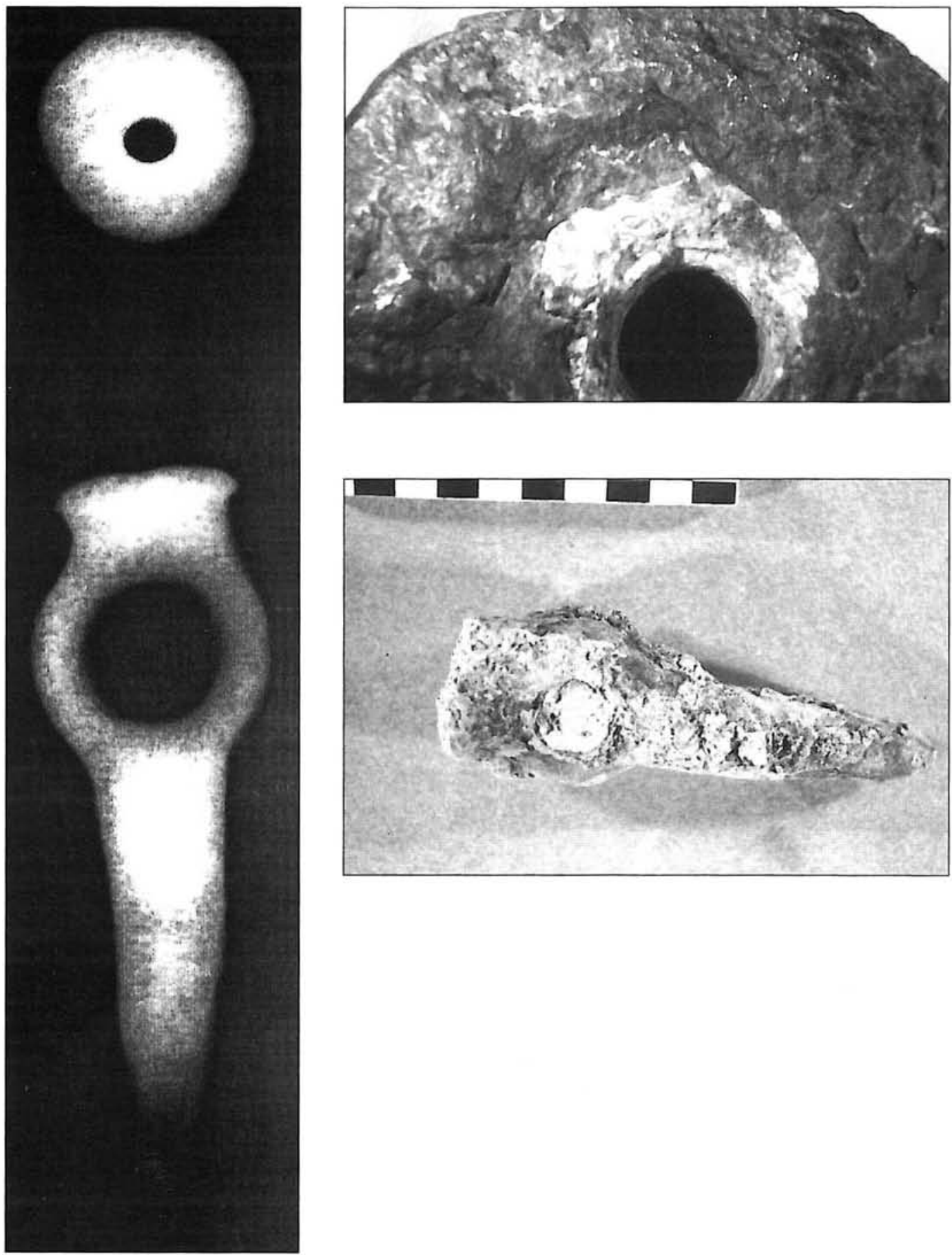

Fig. 7. Martillo tajadera y pesa. Placa RX de las piezas y situación inicial. 
ro que subyacen en la estructura interna de los objetos de hierro, y que difícilmente pueden atisbarse con el análisis radiológicos o microscópicos opticos de la superficie. En alguno de nuestros trabajos anteriores ya pusimos de relieve esta ambivalencia de las metalografias siempre que se hicieran con ciertas condiciones, como ha sido en nuestro caso. Por ello, deseamos indicar que no vale la preparación clásica de la muestra, donde sólo se conserve el núcleo metálico sin el paquete de la corrosión externa, pues de ese modo no se pueden caracterizar ni las irregularidades o heterogeneidades de las estructuras oxidadas ni los compuestos minerales de deterioro que se han formado a partir del hierro metálico; es preciso que la muestra metalográfica abarque tanto las capas de corrosión como el núcleo si lo hay, y a ser posible en seccion completa.

De todo el catálogo referido en el trabajo, las piezas de las que disponemos de metalografías son: vástago curvo ( 2 muestras), punzón, clavo y hoz 1.

En cuanto al văstago curvo, disponemos de dos muestras, la M1 que contiene áun parte del núcleo metálico y la M2 compuesta sólo por el paquete de corrosión. La pieza de un acero hipoeutectoide $(0.15-0,2 \% \mathrm{C})$ estaba elaborada a partir de chatarra o retales de otras piezas; de ahí su gran heterogeneidad que en su día le concedió malas propiedades mecánicas y que a posteriori durante el enterramiento provoca una mayor disposición para la corrosion. La matriz se compone de Ferrita con carburos de hierro precipitados, cuya evolución microestructural con el paso del tiempo les ha agrandado de tamaño (Fig.8).

Resulta interesante reconocer la corrosión en forma de capas porosas con aspecto de corteza de árbol (Fig. 9), una disposición que se debe a que la formación de óxido no es continua sino en periodos cíclicos en que las condiciones del medio son más favorables. Así por ejemplo la formación de Hematita a partir de la Ferrohidrita está muy influencia por las condiciones de $\mathrm{pH}$ y de Temperatura durante el enterramiento prolongado. En distribución la magnetita se presenta antes que la hematita, un óxido que es último producto en la transformación de otros óxidos de hierro (Fig.10). Las grietas que se observan en estas capas se deben al constante cambio de volumen, y se convierten en los canales de penetración de los residuos que transportan las aguas intersticiales, no sólo óxidos de titano o fosfatos (Fig.10, gráfica), como los detectados por análisis de MEB con EDX, sino las tan temidas sales de sodio, presentes en mayor o menor medida en los suelos que también penetran disueltas en el agua.

La segunda pieza es el punzón (¿para el trabajo del cuero?), de cuya metalografia se desprende que es así mismo un acero muy suave con algo menos del $0,15 \% \mathrm{C}$ e impurezas de sulfuro de manganeso. la muestra, que procede de la boca del punzon, detalla una estructura de forja con los granos de Ferrita muy destruídos, cuyo envejecimiento estructural ha provocado una segregación para formar carburo de hierro esferoizado (Fig. 11) Interés a parte muestran las capas de Magnetita, que igual modo se manifiesta en forma de corteza de árbol, con crecimientos discontinuos a lo largo del tiempo y numerosas microfisuras en función de mayor volumen de los productos de corrosión.

El tercer análisis se realizó sobre muestra de la boz 1 Se trata de una muestra completamente mineralizada, salvo unos pequeños residuos metálicos sin repercusión en la resistencia mecánica, con una estructura donde sólo se puede valorar la composición y 


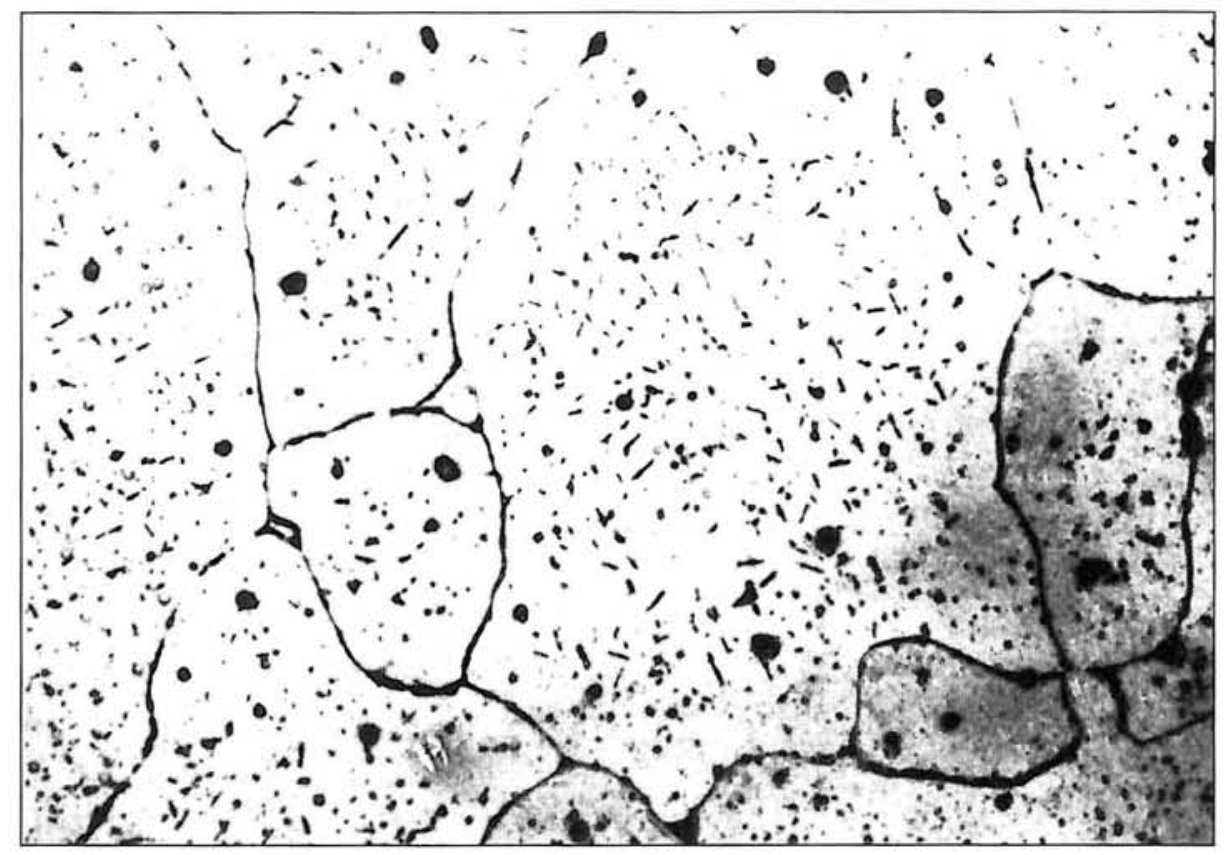

Fig.8. Västago curvo. Metalografía, matriz ferrítica con carburos de hierro.

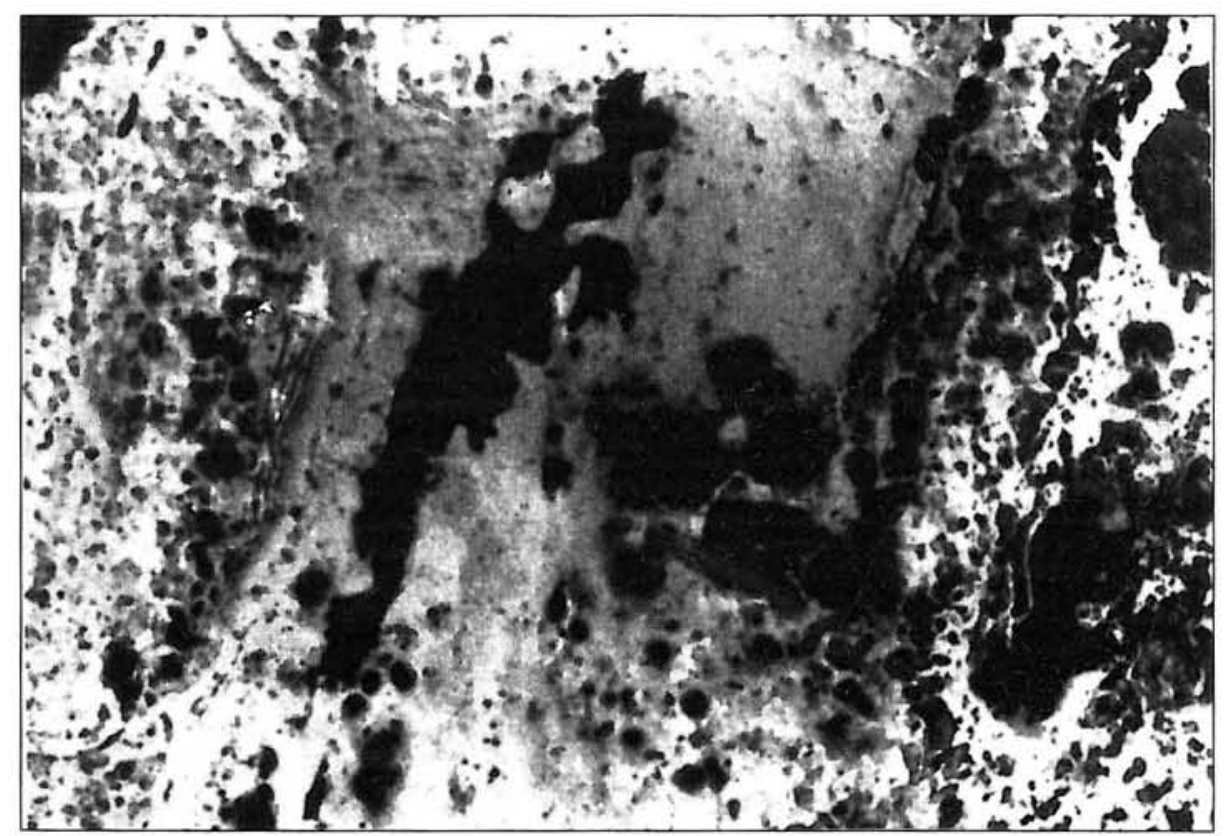

Fig.9. Vástago curvo. Metalografía mostrando el paquete de corrosión poroso. 

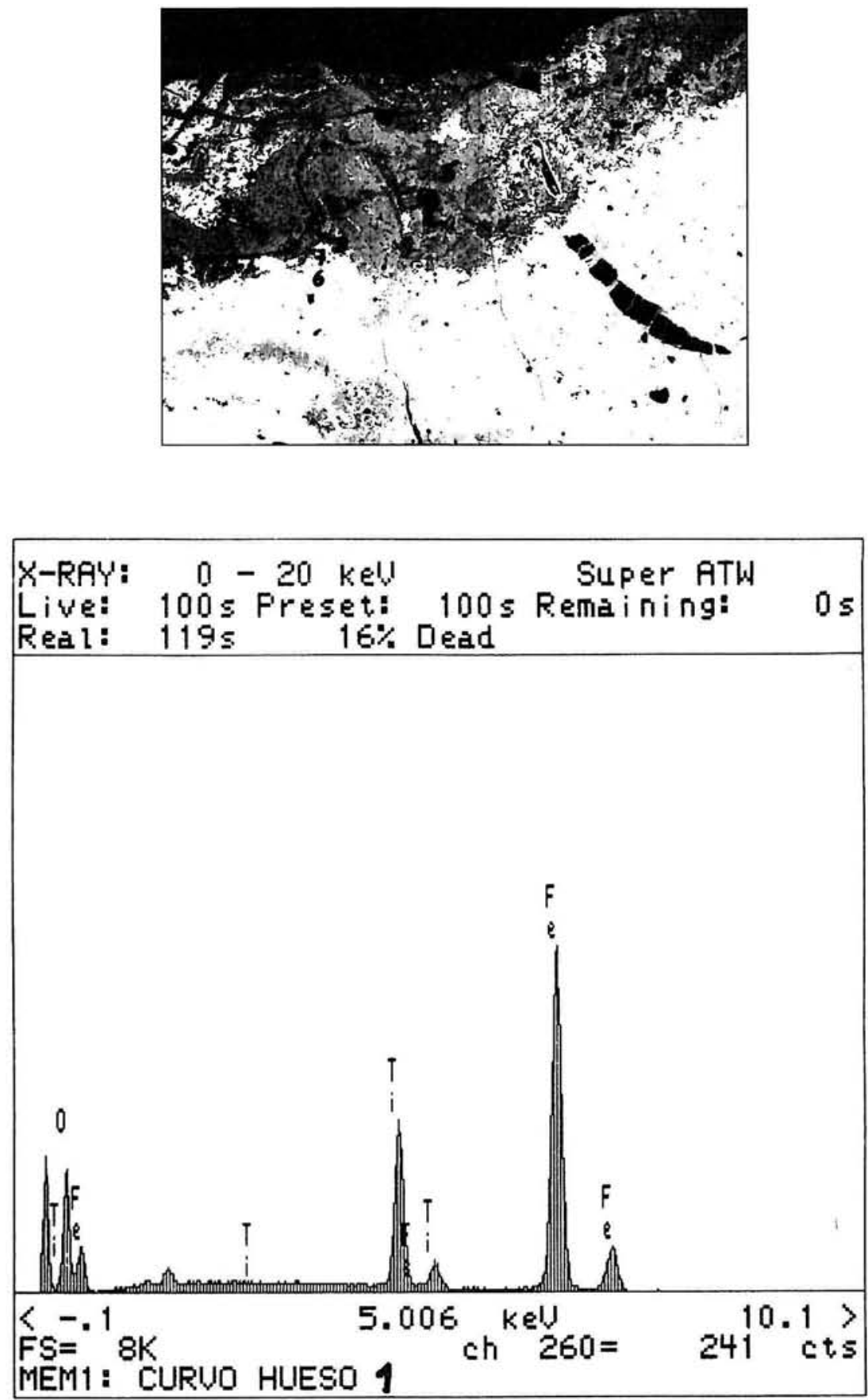

Fig.10. Vástago curvo. Metalografía de capas de corrosión (Magnetita zona clara, Hematita zona obscura), y Gráfica EDX con análisis de inclusiones de titanatos en una grieta. 


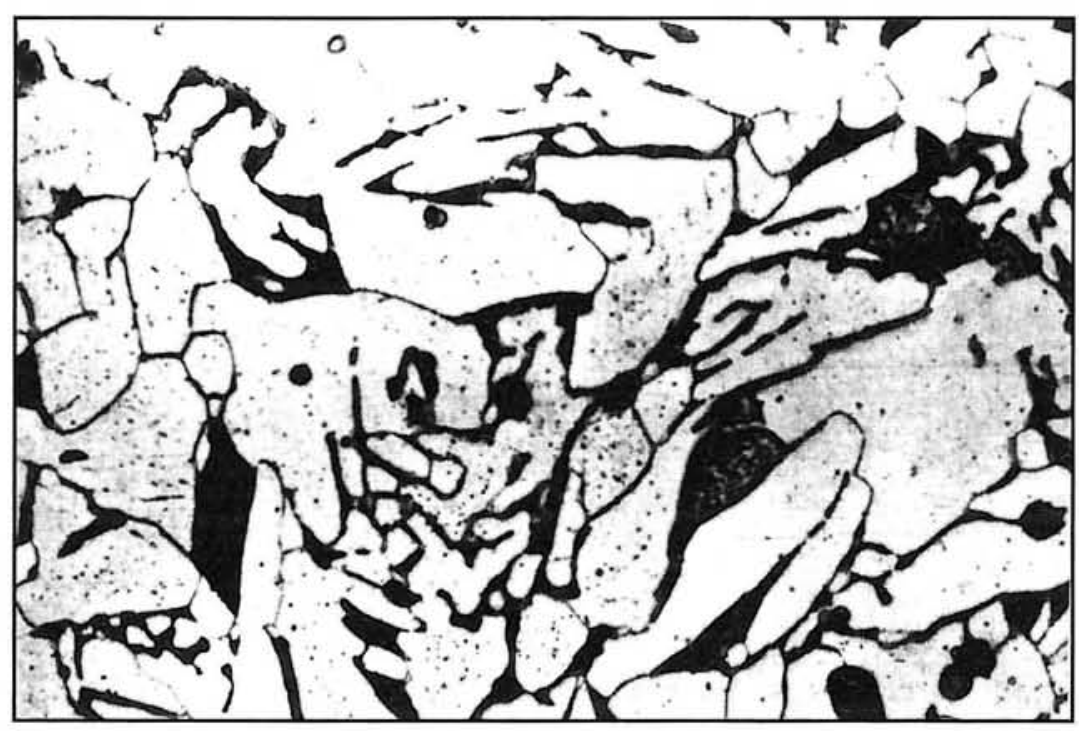

Fig. 11. Punzón. Metalografía de matríz ferrítica con carburos de hierro precipitado.

forma del paquete corroído. Es interesante evaluar como el estado del óxido reproduce la estructura laminar y fibrosa que se creó mediante una forma en caliente, con estiramiento en una sola dirección. La disposición en capas simula una corteza en extremo porosa y fisurada, donde ha sido posible alojar las aguas intersticiales (Fig.12). Las numerosas cavidades son fruto del continuo cambio de volumen de los óxidos, y constituyen los espacios preferentes para la ubicación y crecimiento de los grupos iónicos con presencia de cloro, como veremos seguidamente.

La última de las piezas es un clavo, con una muestra de uno de los extremos completamente oxidada donde sólo se pueden reconocer algún pequeño resto del metal, formado por un acero de bajo contenido en carbono. La misma estructura laminar en capas, de profundas grietas, con la Magnetita en el interior en contacto con los restos del núcleo y la Hematita en la parte externa. En la Magnetita se dibujan con claridad las fibras de la forja, lo que evidencia la relación entre la oxidación y la estructura propia conformada de este acero suave (Fig.13), aunque las condiciones de enterramiento en el interior de esta estancia HE-C deben de haber sido muy agresivas, propicias para una mineralización completa.

En resumen, la valoración final de los análisis metalográficos permite acercarnos a conocer aspectos destacables de la metalurgia de Capote, desconocidos hasta el momento, así como de los procesos de corrosión de las piezas, colaborando ampliar el conocimiento de las características y estructuras de los metales antiguos (France-Lanord, 1980). Cuando conservan núcleo metálico éste corresponde a un acero hipoeutectoide con bajo contenido en carbono $(0,15 \% \mathrm{C})$; es muy posible que hubiese aceros con incide más alto, pero no tenemos constancia metalográfica de ellos. Las condiciones de trabajo se han hecho por 


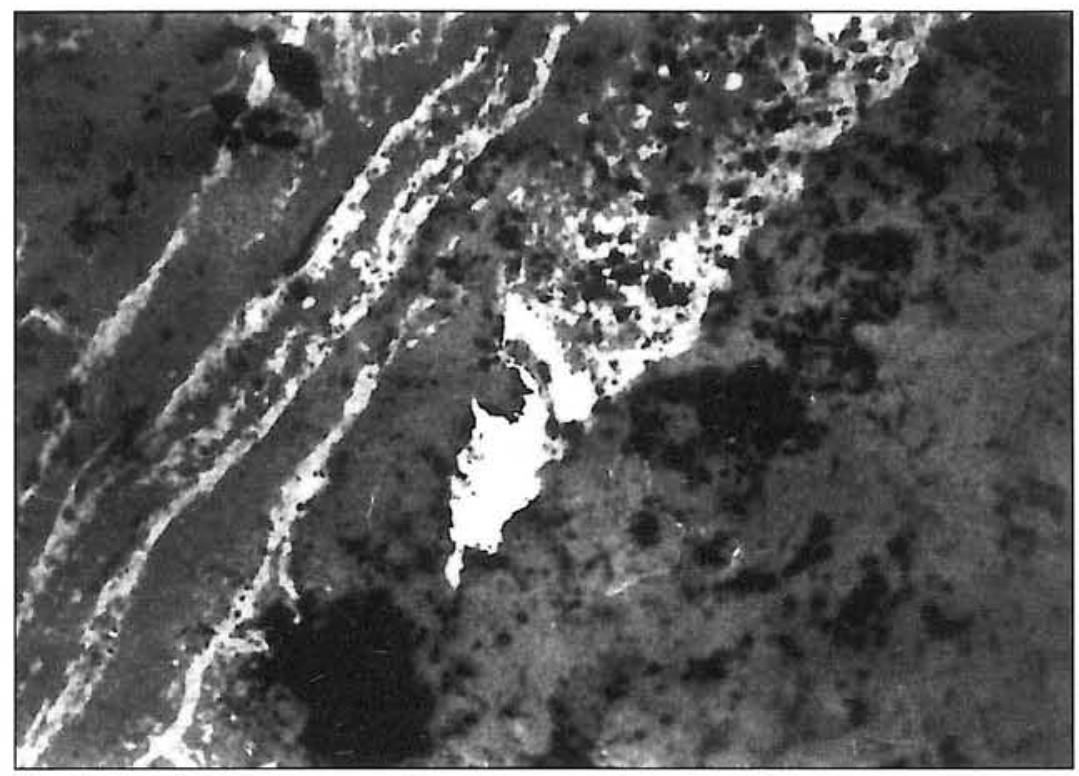

Fig.12. Hoz 1. Metalografía con capas de distintos óxidos y una inclusión metálica residual.

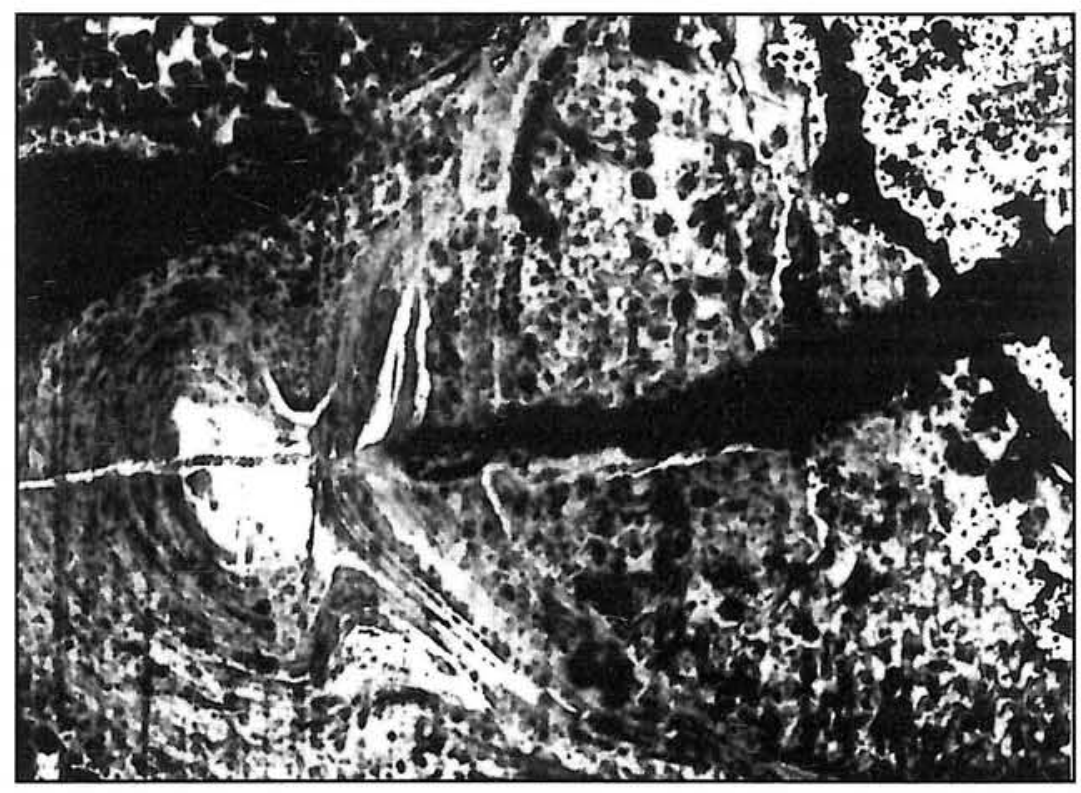

Fig. 13. Clavo. Estructura en corteza de árbol de las capas de corrosión, con grietas penetrantes. 
forja en caliente, ya que hay diferencia de tamaño de grano en la periferia, además de numerosas heterogeneidades donde la Ferrita está muy destruida, propias de una forja donde el herrero local ha aprovechado restos de aceros de contenido en $\mathrm{C}$ variable. Cuando la muestra sólo presenta una estructura corroída o mineralizada al completo, ésta tiene forma de corteza de árbol, porosa y hojaldrada, donde se hallan presentes diversos tipos de óxidos, silicatos, titanatos, o sulfuros de manganeso; éstos son los indicadores de la evolución de la degradación del metal, que se queda impresa en la diferenciación de los productos de deterioro generados. Parece lógico, que para llegar a esta situación hay que pensar en unas variables ambientales muy agresivas en el "medio tierra" (Guichen, 1990, 3340 ), ya que ha propiciado la degradación completa de algunas piezas o ha reducido el núcleo de metal a la minima expresión.

Descle la óptica metalúrgica, las piezas de Capote han sufrido un lento proceso de envejecimiento estructural, pues se ha encontrado carburo de hierro en la matriz ferrítica, que ha evolucionado con el paso del tiempo por un fenómeno de difusión.

Finalmente, la manera de manifestarse el estado de la oxidación pone de relieve una de las premisas más rastreadas en nuestros últimos trabajos, esto es que la tecnología de producción de los hierros forjados antiguos tiene una relación directa en la forma de la oxidación de estos objetos y ésta a su vez en la singularidad de su deterioro mediante el crecimiento fibrilar del volumen y el desprendimiento de láminas. Ello determina, así mismo, el tipo de limpieza y el procedimiento que esta debe de seguir, pues en definitiva para nosotros se trata del objetivo fundamental de nuestro trabajo: la conservación de estos objetos de hierro.

\section{ANÁLISIS DE RECONOCIMIENTO DE DETERIORO POR MICROSCOPIA ELECTRONICA DE BARRIDO (MEB) CON EDX.}

En los últimos años esta metodología de análisis se ha revelado como una de las mejores herramientas para el diagnóstico del estado de conservación de los objetos arqueológicos que precisan ser intervenidos, y muy en especial en lo que se refiere a los metales, que como hemos ido viendo ofrecen una problemática complicada. Segín ha quedado de manifiesto en trabajos anteriores, algunos aquí citados, para nosotros ha sido y sigue siendo una herramienta de una utilidad extraordinaria. En el Laboratorio correspondiente del SIDI de la UAM se cuenta ya con la experiencia necesaria para realizar con éxito una analítica con muestras tan específicas ${ }^{\text {i31. }}$.

El estado de conservación de los hierros de Capote nos ha permitido disponer de numerosas muestras en forma de pequeñas esquirlas desprendidas de la superficie o bien de fragmentos de un tamaño reducido; hemos seleccionado aquellas que ofrecían un con-

[3] Deseamos dejar patente nuestro agradecimiento a la lalor de Dô" Esperanza Salvador, Técnico del MEl3 del SIDI de la UAM, por su continuado y creciente interés en sacar el máximo particlo a nuestros hiemos, a pesar de los numerosos problernas que estas muestras han presentado. 
tacto claro con la pieza restante, una vez retiradas las tierras superficiales que no son conductoras. Salvo en el caso de las muestras metalográficas más arriba detalladas, nunca se ha provocado voluntariamente la pérdida de muestra. En este sentido, puede decirse que la Microscopía se ha utilizado como si de un END se tratase, pues las esquirlas tomadas como muestra pueden volver a reponerse en su lugar si se considera obligado en el proceso de restauración de la pieza.

No todas las piezas del catálogo de hierros disponible de Capote fueron analizadas por MEB; pero se puede considerar representativo el número del que ofreceremos los resultados de la analítica, apoyado en los documentos gráficos necesarios para su confirmación.

El objetivo fundamental ha sido buscar la existencia de iones de cloro entre el paquete de óxidos, hidróxidos y carbonatos de hierro que determinan el grueso de su corrosión, habitual en este tipo de objetos de época prerromana procedentes de excavaciones terrestres. En segunda instancia se trataba de poder localizar, si era posible, los puntos exactos de la estructura donde se ubicaban los cristales de estos compuestos de hierro y cloro, así como la singularidad que ésta presentaba debido a los fenómenos corrosivos. De este modo, se ha aprovechado tanto la detección óptica microscópica que da información morfológica como la valoración analítica, teniendo en cuenta siempre que se trata de una análisis elemental y no de los compuestos concretos. Para realizar esta comprobación efectiva hemos acudido en un par de casos a una técnica de MicroDifracción de $\mathbf{R X}^{\text {(1) }}$ que nos ha permitido verificar nuestra presunción, y complementar los datos de MEB.

La pieza sobre la que hemos centrado una mayor atención de análisis por MEB ha sido la denominada $\mathrm{Hoz} 2$; de ella en su día se realizó un estudio monográfico (Barrio, $1996,930-934$ ), que hoy queremos y podemos ampliar con datos más precisos y confirmados en nuevos análisis.

Como se indicó nuestro interés preferente estaba centrado en reconocer los elementos presentes entre las láminas de hierro producidas por la forja de la hoz, ya que el proceso de escamación parecía progresivo y, conforme la percepción visual en lupa binocular, este efecto se constataba producido por el empuje interior que hacía saltar la capa superficial. Ver qué elementos ocasionaban tal presión era nuestro objetivo principal.

De los resultados documentales obtenidos, recogidos en fotografías de una sección transversal a fractura abierta (Fig.14), puede observarse la presencia de grandes cristales de minerales de hierro donde hay iones $\mathrm{Cl}$ que presionan sobre las paredes de la estructura de este metal, suponemos que con un empuje efectivo que provoca el consecuente desprendimiento de las escamas del hierro, en este caso totalmente mineralizado. La comprobación de los datos cuantitativos puede verse en el respectivo espectrograma (Fig.14 gráfica). No presentamos el mapa de la dispersión en gráfica, al no ser significativo, ya que toda la masa de hierro de la muestra está infectada de $\mathrm{Cl}$.

[4] Los anälisis fueron realizados por el Dr. Martín Rubí en el ITGME, a quien deseamos reconocer su apoyo y colaboración. 


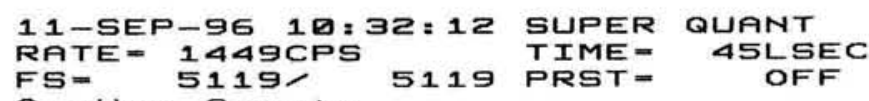

A. =Hoz Capote
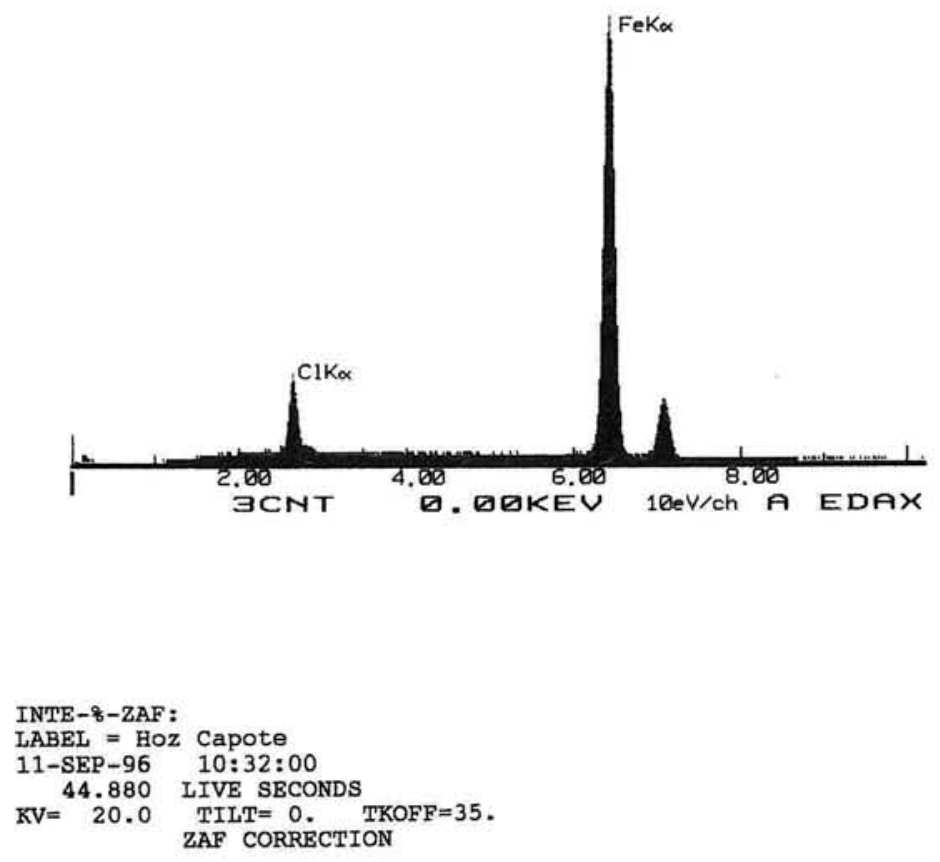

ELEM K $\quad$ Z $\quad$ A $\quad$ F

CLK $0.0586 \quad 1.065 \quad 0.767 \quad 1.008$

FEK $0.9205 \quad 0.995 \quad 0.996 \quad 1.000$
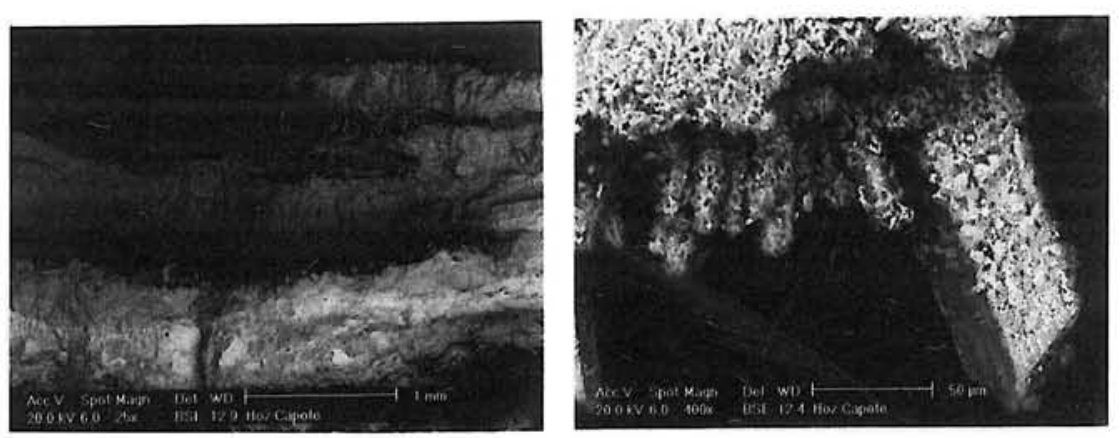

Fig.14. Hoz 1. Análisis MEB con EDX, con macrofotografía de cristales de Akaganeita, ubicados en las cavernas del hierro mineralizado. 
Tal como ya apuntábamos, con alta probabilidad la causa de la cristalización de estos compuestos con $\mathrm{Cl}$, grupo iónico que invade la masa de hierro en forma de colonia vigorosa y activa, se deba a las condiciones del proceso post-excavación. La reducción de los elevados niveles de HR que ese objeto de hierro tuvo en el medio "tierra", posiblemente durante el enterramiento superiores al $90 \%$ y de notable estabilidad, así como la existencia en la pieza de zonas donde el proceso de alteración ha creado espacios abiertos útiles para el crecimiento de cristales son, sin duda, las dos variables que lo han hecho posible. Las condiciones de sequedad aceleran indudablemente esta situación, cuyo punto final desconocemos, pues en las cavidades aún hay espacios para la disposición de nuevos cristales. En cuanto al lugar donde se localizan dentro de la sección laminar de la pieza, tiene un notable interés y resulta muy novedoso, pues no parece nada fácil localizar microscópicamente estas formaciones ubicadas en sus propias cavidades de crecimiento.

Para la caracterización final de estas masas de cristales con iones de $\mathrm{Cl}$ presentes en el hierro, se ha llevado a cabo un análisis de MicroDifracción de RX a fun de comprobar la identidad concreta de los compuestos que tiene la hoz en los espacios abiertos interlaminares (Fig. 15). El protocolo metodológico se ha detallado en casos parecidos con un resultado positivo (Arnauld-Pernot et al., 1993, 102-108). Para ello se ha tomado una parte pequeña de la muestra de MEB, extrayendo el máximo de materia del interior de estas cavernas, que ha sido preciso reducir a polvo para el preparado del porta del análisis. Los resultados son muy elocuentes: estamos ante Akaganeíta más trazas de Lepidocrocita, Goetita y Magnetita. De ellos sólo la Magnetita se presenta como un producto estable, pues los otros son hidroxidos que siempre se muestran muy inestables, especialmente la Akaganeíta, que retiene una cantidad importante de $\mathrm{Cl}$ en su composición, lo que provoca cambios en su volumen y cristalización debido a las variaciones de HR ambiental. En peso atómico la masa de Cloro es muy importante llegando a suponer el $10 \%$ como se verifica en el análisis de EDX presentado con antelación. Este dato de nuevo pone en evidencia que la combinación de técnicas arqueométricas permite una evaluación más certera de los problemas de corrosión (Ouahman et al., 1998, 172-173), puesto que ya en MEB se habían podido detallar las estructuras arborescentes de este compuesto, la Akaganeíta, tan peligroso para el futuro de los hierros de esta época, y a la vez tan omnipresente en ellos, como hemos comprobado en trabajos nuestros ya citados, y machaconamente confirmado por la bibliografía del tema.

En segundo lugar interesa referirse al Clavo, pues en este caso también disponemos de analítica por MEB con EDX y de MicroDifracción de RX. Para la muestra se ha cogido una lámina desprendida de la parte superior, cercana a la cabeza, que ya en el análisis óptico con binocular estereoscópico se había mostrado con muchas posibilidades de tener este compuesto (Fig.16).

En la gráfica que presentamos y en el análisis de EDX puede percibirse la existencia de un conjunto de elementos que están presentes de manera habitual en los paquetes de corrosión de los hierros, donde no sólo hay hierro ya mineralizado con presencia de iones $\mathrm{de} \mathrm{Cl}$, sino el registro lógico de las tierras y carbonatos que se han recuperado durante el enterramiento. La cuantificación de estos elementos nos coloca el $\mathrm{Cl}$ entre un 9,67 y un $10,28 \%$, en la línea de los registros anteriores. 


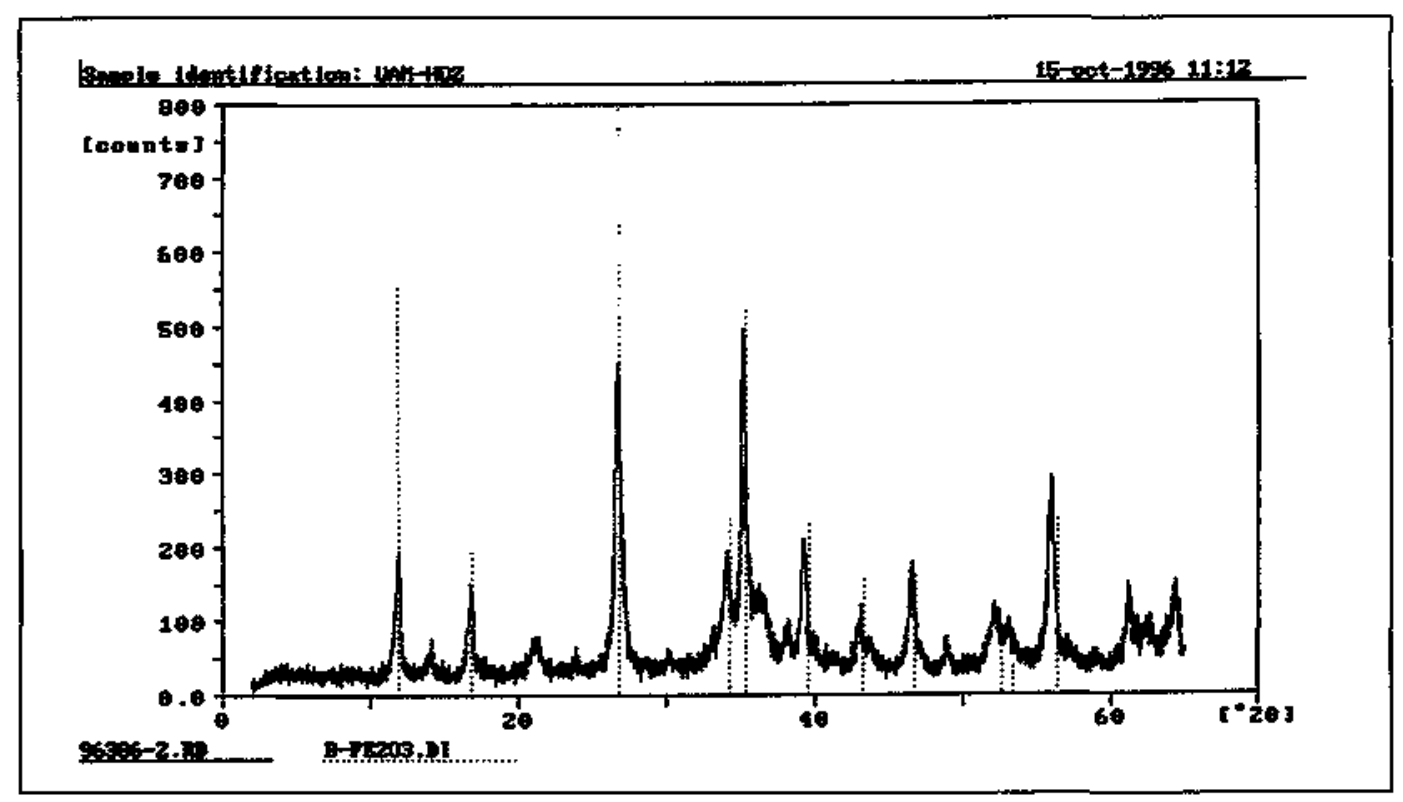

Fig. 15. Hox 1 Espectograma de un análisis de DRX con detección de Akaganecita.

La confirmación de la identidad concreta de estos compuestos se ha realizado igualmente mediante un análisis de MicroDifracción por el mismo Laboratorio que en el caso de la Hoz. El resultado también supone la constatación de la existencia de Akaganeíta, Magnetita y Goetita, así como trazas de Lepidocrocita y de Hematita.

En cuanto al martillo tajadera (denominado en las gráficas y espectrograma pico), la investigación se ha producido a partir de una sola muestra; teniendo en cuenta la integridad del objeto no era viable provocar la toma de otra lasca, puesto que el martillo, como ya comprobamos en las placas radiográficas, mantenía casi intacta la película externa original, ahora transformada en una capa muy homogénea de magnetita. En la microfotografía (Fig.17) se puede observar el desprendimiento de la esquirla desde un cráter de corrosión localizada, con las microfisuras típicas provocadas por el aumento de volumen de los oxidos, que han crecido a la manera de una corteza de árbol. La escamación se ha producido por los empujes de los cristales de minerales de hierro desde el núcleo hacia el exterior, pues se observan las líneas de esta mayor presión así como la microexfoliación consiguiente.

En la gráfica del análisis de EDX extrañamente no aparecen restos de $\mathrm{Cl}$, sino sólo compuestos de hierro; por tanto cabe la posibilidad de que en este punto de la pieza la escamación la hayan provocado los oxihidróxidos en su crecimiento volumétrico o bien que los cristales de hierro con iones cloro se hayan quedado adheridos en la pieza. Sin embargo, lo que nos ha parecido más destacable es la presencia de $\mathrm{Pb}$ que se reconoce en los puntos más brillantes del documento gráfico, ubicados por tanto en zonas fisuradas muy externas. Además, en peso atómico \% tiene una notable relevancia. 


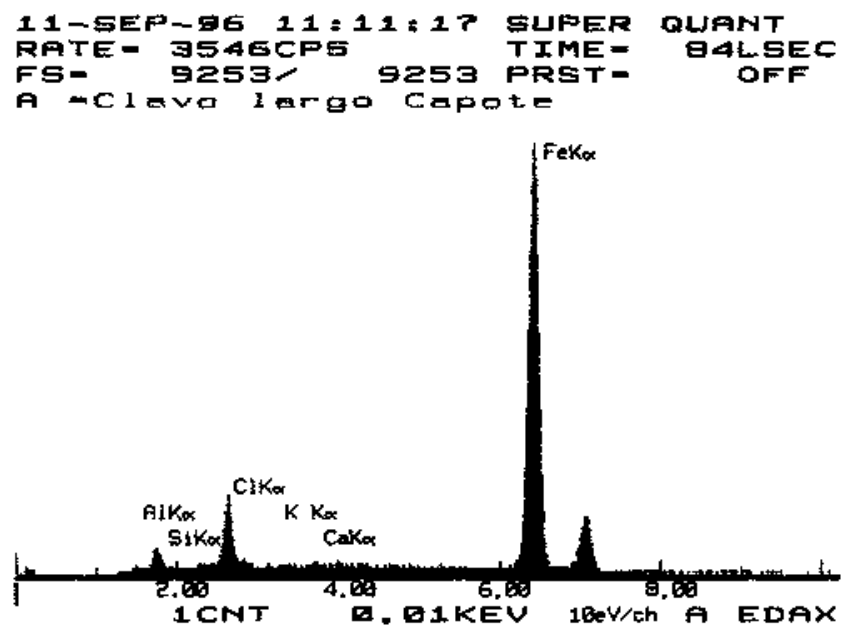

INHB-8-2AF :

LABEL = Clavo largo capote

11-8EP-96 11:13:59

84.049 IIVE

KV= 20.0 TIIT= 0. TMOF $\mathrm{F}=35$.

WAF CORRECTION

BLEN $\mathbb{R} \quad \boldsymbol{Z} \quad$ A $\quad \boldsymbol{F}$

CLR $0.0558 \quad 1.065 \quad 0.767 \quad 1.008$

PEK $0.9242 \quad 0.995 \quad 0.996 \quad 1.000$

$\begin{array}{lcr}\text { FLKKM } & \text { CPS } & \text { AT } \\ \text { CL K } & 150.0264 & 10.28 \\ \text { FE K } & 1271.0261 & 89.72 \\ \text { TOTAE } & & \text { I00.00 }\end{array}$

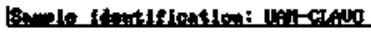

$15-9,15-199 \times 11: 15$

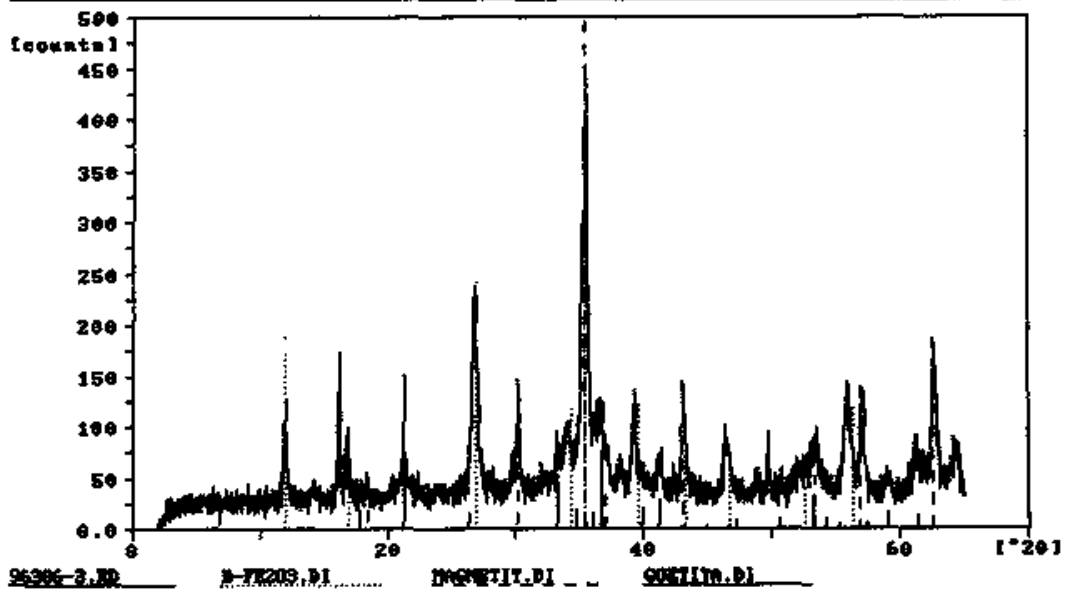

Fig. 16. Clato. Espectogramas de MEB con EDX, con indicación de productos de corrosión. 


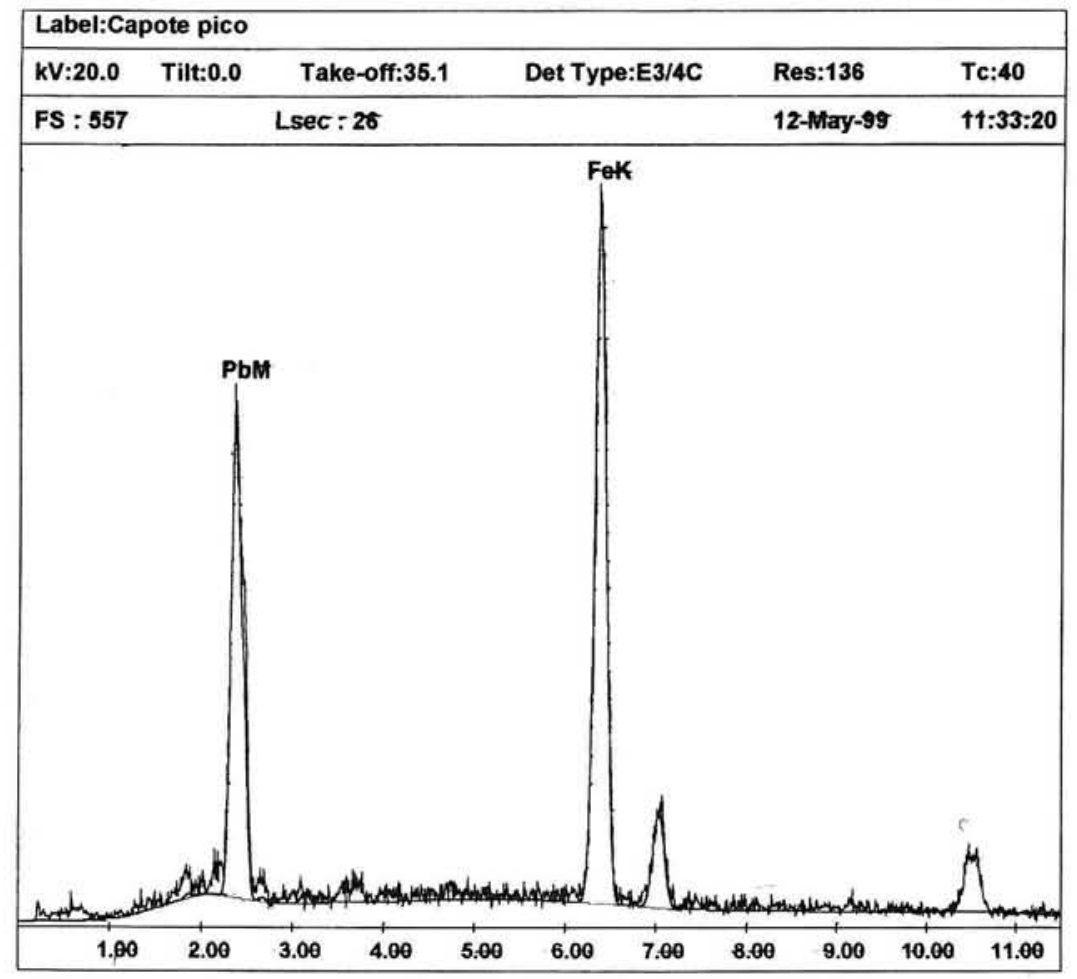

\begin{tabular}{|rrrrrrr|}
\hline Element & Wt\% & At $\%$ & K-Ratio & Z & A & F \\
\hline PbM & 46.82 & 19.18 & 0.3949 & 0.8544 & 0.9871 & 1.0000 \\
FeK & 53.18 & 80.82 & 0.5472 & 1.0948 & 0.9329 & 1.0074 \\
Total & 100.00 & 100.00 & & & & \\
\hline
\end{tabular}
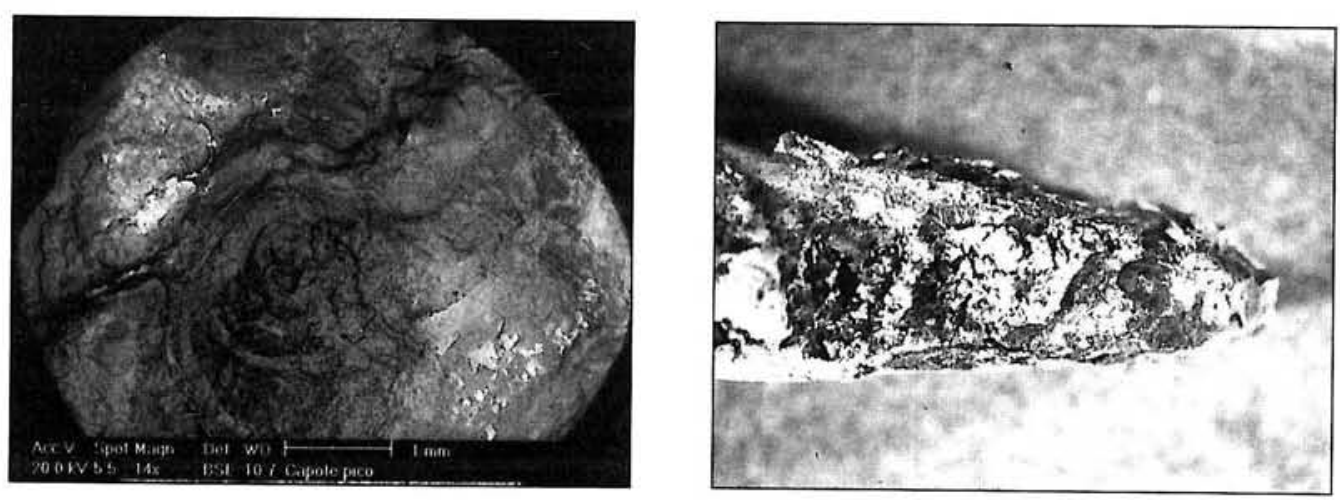

Figura 17. Martillo Tajadera (pico). Análisis de MEB con EDX, y detalle óptico del foco de corrosión en la punto donde había inclusiones de $\mathrm{Pb}$. 
Por ello, hemos estudiado con cierto detalle los análisis de microsonda realizados a las escorias de Capote, efectuadas además en el mismo equipo MEB que nuestras muestras, y en ninguna de ellas aparecen restos de $\mathrm{Pb}$ entre la larga serie de elementos presentes (Gómez Ramos, 1995, 679-683). Interpretamos por ello que es muy posible que se trate bien de deposición de residuos geológicos llegados a estas zonas superficiales durante el enterramiento de la pieza o bien de una contaminación de la tajadera durante el trabajo en la forja, pues como se ha comprobado en la pesa llevaba $\mathrm{Pb}$ en el orificio central. Además la lámina objeto de la analítica se han tomado de la parte más externa, y se habían separado del núcleo mediante una fisura longitudinal. Por otra parte, las caracteristicas de este martillo tajadera, encontrado completo y con un vigoroso núcleo metálico, no nos han permitido hacer un análisis metalográfico a partir de una sección de la pieza, con lo cual se hubiera podido comprobar cuál era el grado de intromisión o presencia de este metal, ajeno en el proceso de fundición de los minerales del hierro.

También poseemos una análisis puntual del Cucbillo 1, a partir de una pequeria lasca desprendida de la zona de la punta, donde a través de la radiografía se comprobaba una zona con menor núcleo metálico y determinada por una corrosión localizada en forma de pequeños puntos o cráteres. En este caso la microfotografía (Fig. 18) nos muestra una superficie hojaldrada y porosa, llena de fisuras, donde queda patente la irsegularidad de los productos de deterioro del hierro. En este caso sí pudimos localizar la presencia de iones de $\mathrm{Cl}$, que en peso atómico se acercan al $4 \%$ (Fíg.18 gráfica). Ello sin duda manifiesta la presencia de Akaganeíta, de cuya inestabilidad ya hemos hablado en línea precedentes, causa de los serios problemas de piezas como ésta. En un mapa de dispersión de $\mathrm{Cl}$ en toda la muestra pudimos comprobar que los focos clorurados estaban concentrados en la parte superior de ésta, en la línea de contacto con el plano de desprendimiento, por lo que nos hace pensar que el crecimiento de los cristales se produce desde el interior, esto es alimentados desde el núcleo metálico, por lo cual éste, o al menos las fisuras, se encuentran infectados.

Como en el caso del martillo tajadera se reconoce la presencia de $\mathrm{Pb}$, que se localiza en la parte inferior, más clara, del documento microscópico, recorriendo un plano de fisura; porcentualmente en peso atómico no es alta, entre el 1,1 y $2,81 \%$ (en segundo análisis EDX). A la luz de este nuevo dato, cabe modificar la argumentación referida en líneas precedentes sobre el origen de este metal, ya que el cuchillo no ha sido una herramienta del herrero. Por tanto, habría que concluir que estos compuestos de $\mathrm{Pb}$ podían haberse introducido a partir de los componentes geológicos disueltos en el agua, fácilmente difundidos a partir de las microfisuras que genera el cambio volumétrico y estructural de la corrosión de los productos de alteración del hierro.

En cuanto al vástago curvo, hemos contado con un lámina tomada de la zona intermedia, donde aún conserva parte del núcleo metálico. Como vimos en su momento mediante la metalografía se había podido reconocer el tipo de material metálico, un acero hipoeutectoide, así como el catálogo, la forma y la evolución de óxidos y oxihidróxidos de hierro que integraban el paquete de la corrosión, así como la forma y evolución de éstos. El aspecto de la muestra es poroso con múltiples fisuras y áreas de agrietamiento, fruto de la presión mecánica ejercida desde el interior y de las contracciones debidas a la pérdida de agua (Fig.19). 


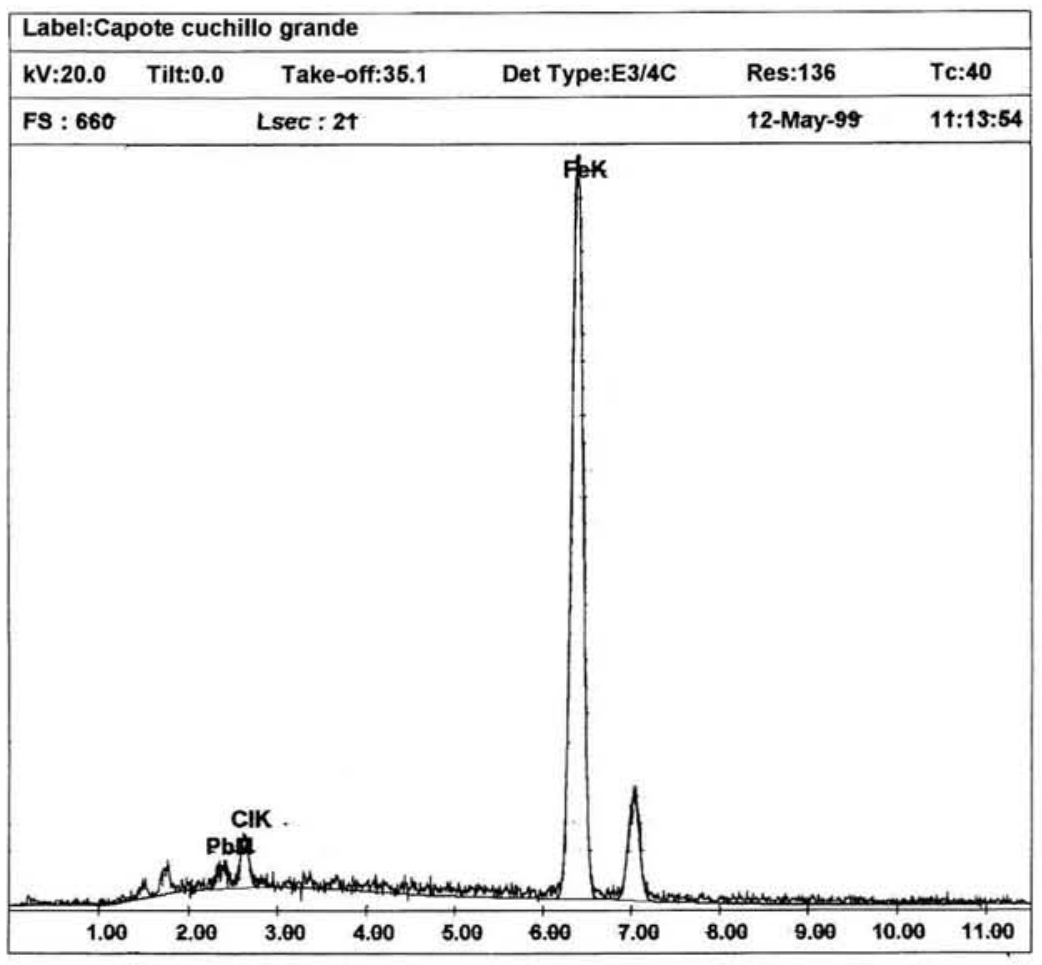

\begin{tabular}{|rrrrrrrr|}
\hline Element & Wt\% & \multicolumn{1}{c|}{ At\% } & \multicolumn{2}{c|}{ K-Ratio } & Z & A & F \\
\hline PbM & 4.01 & 1.10 & 0.0301 & 0.7798 & 0.9615 & 1.0001 \\
C1K & 2.48 & 3.96 & 0.0196 & 1.0761 & 0.7304 & 1.0081 \\
FeK & 93.51 & 94.94 & 0.9334 & 1.0050 & 0.9925 & 1.0008 \\
Tota1 & 100.00 & 100.00 & & & & \\
& & & & & & \\
\hline
\end{tabular}

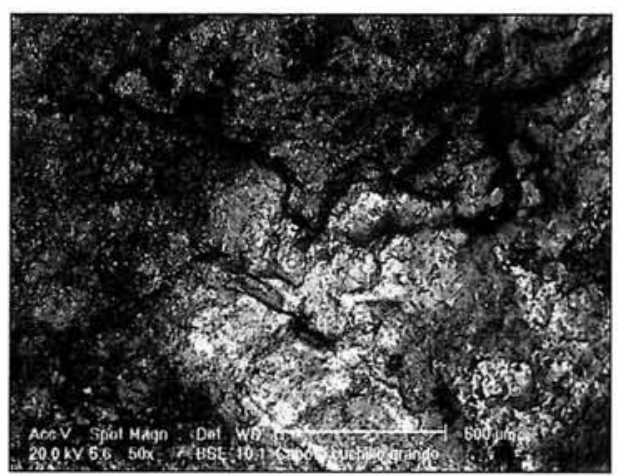

Fig. 18. Cuchillo Gráfica de MEB con análisis de EDX de elementos de la corrosión, y microfotografía de productos agrietados. 


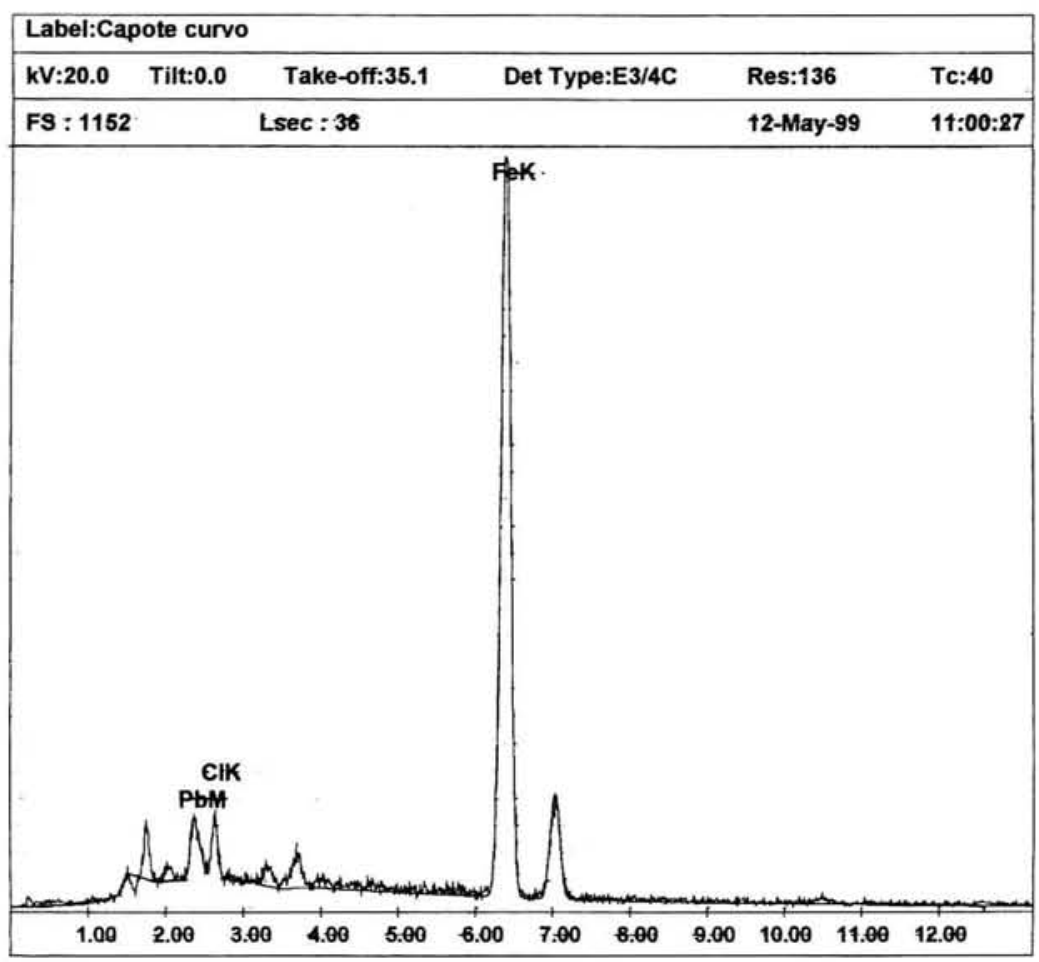

\begin{tabular}{|rrrrrrr|}
\hline Element & Wt\% & \multicolumn{1}{c|}{ At\% } & K-Ratio & Z & A & \multicolumn{1}{c|}{ F } \\
\hline PbM & 9.51 & 2.71 & 0.0725 & 0.7876 & 0.9671 & 1.0001 \\
C1K & 2.65 & 4.42 & 0.0203 & 1.0864 & 0.6992 & 1.0068 \\
FeK & 87.83 & 92.87 & 0.8786 & 1.0144 & 0.9843 & 1.0018 \\
Total & 100.00 & 100.00 & & & & \\
\end{tabular}

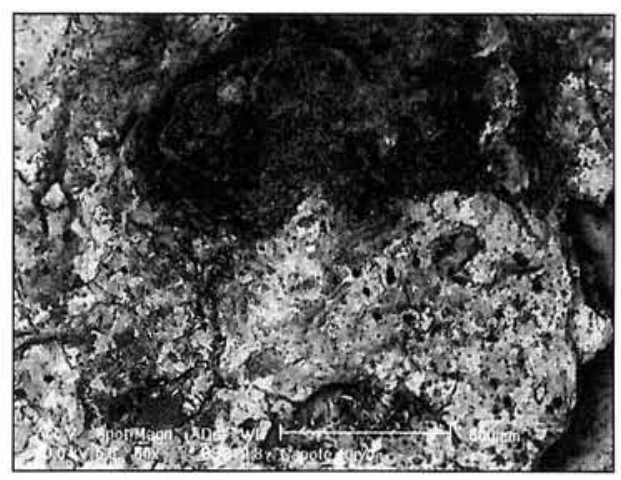

Fig. 19. Vástago curvo. Análisis de MEB con EDX, y detalle óptico del foco de corrosión en la punto donde había inclusiones de $\mathrm{Pb}$ y $\mathrm{Cl}$. 
Ahora con MEB ha sido posible determinar elementos que entonces no se habian detectado. Especial interés tiene la localización de $\mathrm{Cl}$, en una cantidad muy notable, 4,42\% de atómico, que deben integrarse en los cristales de Akaganeíta, tan responsables de la corrosión localizada en forma de cráteres que se observan a lo largo de la superficie de esta pieza de hierro. El segundo espectrograma de EDX nos ofrece un dato novedoso, pues se ha localizado (zona obscura inferior izqda de la microfotografía) un foco con carbonatos y fosfatos; éstos últimos ya detectados en el análisis EDX de la segunda metalografía más arriba referida. Como entonces comentamos, citando el informe del Prof Criado, la presencia de todos estos elementos inmersos en el paquete de óxidos se deba a la llegada de aguas intersticiales, que se introducen en las fisuras cuando la corrosión ya ha hecho un trabajo efectivo. No obstante, en lo referente al $P$, haya que decir que también pueda deberse a un residuo del proceso técnico de obtención del hierso.

A modo de puntualización final de esta analítica de MEB con EDX, el resultado más sorprendente para las personas que hemos participado en ella no es otro que la perfecta comprobación del crecimiento de los cristales de cloruro en una pieza arqueológica de hierro premromano producida mediante forja. Así mismo, la inserción de esta masa de cristales en los puntos donde el tratamiento termomecánico presenta una estructura más heterogénea en sección. Y todo ello, siendo posible conseguir una documentación fotográfica excelente, además del registro en gráfica y de la determinación cuantitativa. Por desgracia al tratarse de un fragmento totalmente mineralizado no podemos comprobar el efecto del crecimiento de los cristales con $\mathrm{Cl}$ sobre una masa con buen núcleo metálico.

\section{CONSIDERACIONES Y VALORACIÓN FINAL}

A modo de conclusión final, y dejando de lado la reiteración de los datos analíticos ya referidos, deseamos puntualizar sobre la utilidad de los diagnósticos axqueométricos de cara a efectuar unos tratamientos más adecuados en la conservación y restauración de objetos de hierro como los de Capote, aquejados de un estado de deterioro muy notable.

La arqueometría para el diagnóstico de los problemas de deterioro a partir de datos cuantitativos, cualitativos y estructurales no precisa de una técnica en exclusiva, ni existe en método ideal, sino una combinación de diversos procedimientos y técnicas que se apoyan unos en otros cubriendo las lagunas, y haciendo posible la comprobación mutua. Así mismo, el protocolo para su utilización debe de venir dado por las necesidades de las piezas objeto de los procedimientos de restauración/ conservación, aunque el apoyo en la investigación básica, con experiencia en múltiples ciencias, es imprescindible. En el caso presentado aquí de los hierros de Capote hemos podido combinar Metalografia Óptica, MEB con EDX, MicroDRX y Radiografía, que nos han aportado datos complementarios para llevar a una mejor evaluación del deterioro de los objetos. Pero sin duda hay muchas más técnicas arqueométricas que desde sus ámbitos propios generarân resultados en este tipo de diagnósticos.

En este sentido, nos cabe plantear una serie criterios para obtener buenos resultados en el momento de articular y definir la aplicación de estos análisis arqueométricos en la conservación de metales antiguos: 
- No utilizar análisis que procuren a la pieza la menor destrucción; lo ideal son las técnicas de Ensayos no Destructivos (END). En todo caso se pueden aprovechar muestras desprendidas de las capas de corrosión. Optimizar la utilización de las muestras aplicándolas, a ser posible, a varias técnicas.

- Diagnosticar, al menos cualitativamente, los elementos existentes en los productos de deterioro del hierro, con especial interés por la presencia del $\mathrm{Cl}$.

- Determinar los compuestos iónicos que generan el mayor deterioro del objeto, bien conocidos en deontología profesional, asi como las variables medioambientales que pueden contribuir a su mayor actividad.

- Comprobar la distribución, inserción y localización de los elementos químicos en la estructura metálica o mineralizada de los objetos de hierro.

- Extremar el reconocimiento cualitativo y estructural de la película original del hierro, por ser éste el valor estético y documental más importante de las piezas.

- Procurar verificación a modo de "contraanálisis" en una técnica distinta cuando se trate de un problema relevante, con notable incidencia sobre la intervención a realizar en la pieza.

- Decidir la aplicación de esta analítica arqueométrica mediante una propuesta de tratamiento de conservación o restauración de los elementos objetivo de la investigación.

A modo de apostilla, indicar que el objetivo final de todos los trabajos que se acometan en este campo no son los procedimientos arqueométricos en sí mismos sino el futuro y la vida de los objetos de hierro, aunque se trate de conocimientos instrumentales cada vez más irrenunciables en el desarrollo de las técnicas de conservación y restauración del Patrimonio Arqueológico Metálico. 


\section{BIBLIOGRAFIA}

ALONSO et al., (1999): Nuevas técnicas metalüricas en las armas de la II Edad del Hierro, Diputación Foral de Alava.

ANGELINI et al. (1998): "Effect of burial soils on the decay of iron artefacts", en Proceedings of The International Conference on Metal Conservation. Metal 1998, ICOM, Draguignan, France. Edt. James \& James (Science Publishers), London, 106-110.

ANTELO/GABALDON (1997): "Algunos aspectos sobre la Radiografia y otras técnicas de análisis no destructivos aplicadas al estudio de los Bienes Culturales en el IPHE. Rev. Dyma, $n^{\circ} 6$, Técnica y Artejul-Agos, Sept. 121-125.

ARNOULD-PERNOT et al (1993): "Optimisation diun traitement de dechloruration d'objets archaeologiques ferreux par plasma d'hydrogene", en Actes de la 7 rencontre annuelle du groupe de travail. Groupe ICOMCC-SFIC. SETCION METAL. Draguignan, 93-111

BARRIO, J. (1989): "La metalurgia del hierro del periodo prerromano. Análisis de las causas de deterito y problemática de conservación" Boletin Auriense. vol. XVIII-XIX, 407-433.

BARRIO, J (1994): "Proyecto de conservación/ restauración de un cuchillo afalcatado de hierro de El Castrejón de Capote (Badajoz)", en Berrocal Rangel, L. El Altar prerromano de Capote, Universidad Autónoma de Madrid, 303-306.

BARRIO, J. (1996): "Metodología de investigación en los procesos de deterioro de los hierros prerromanos", en Actas del XI Congreso de Conservación y Restauración de Bienes Culturales, Castellon, vol.II, 921-936.

BARRIO, J. (1997): "El Patrimonio Arqueológico: un campo abierto a la aplicación técnica." Rev. Dyna, $n^{\circ} 6$, Técnica y Arte. Jul-Agos, Sept. 11-120.

BARRIO/HERMANA (1998) "Méthode de conservation et restauration d'une Falcata ibérique de la nécropole de El Salobral (Albacete, Espagne), en Proceedings of The International Conference on Metal Conservation. Metal 1998, ICOM, Draguignan. Edt. James \& James (Science Publishers), London, 177-184.

BARRIO ET AL. (1999): "Técnicas de Radiología y estado de conservación de hierros prerromanos", $9^{\circ}$ Congreso Nacional de END, Vitoria, 239-247.

BERROCAL RANGEL, L. (1992): Los pueblos célticos del Suroeste de la Península lbérica. Rev. Complutum. Extra 2. Universidad Complutense de Madrid.

BERROCAL RANGEL, L. (1994): El Altar prerromano de Capote, Universidad Autónoma de Madrid.

BARRIL, M. (1992): "Instrumentos procedentes de Soria en el Museo Arqueológico Nacional", Boletín del Museo Arqueológico Nacional, X, 5-20.

BERTHOLON, R. (2001): "The location of the original surface, a review of the conservation literature", en Proceedings of The International Conference on Metal Consenvation. Metal 2001, ICOM, Santiago de Chile, Chile, en prensa.

BERTHOLON/RELIER (1990): "Les métaux archéologiques", en Berducou, M.Cl. (Ed.) La conservation en Arcbéologie. Ed. Masson. Paris. 163-221.

CILIBERTO \& SPOTO (Eds.) (2000): Modern Analytical Methods in Ant and Archeology, Cbemical Analysis vol. 155. Wiley-Interscience.USA 
CRIADO et al. (1998): Estudio metalográfico de piezas metálicas extraidas en excavaciones realizadas en Villanueva de Teba, Capote y Numancia. Grupo de Tecnología Mecánica y Arqueometalurgia, Dpto. de Ciencia de los Materiales e Ingeniería Metalúrgica, Facultad de Ciencias Químicas, UCM, Madrid. Informe Inédito.

FRANCE-LANORD, A. (1980): Métaux anciens, stmucture et caractéristiques., ICCROM. Roma. GILARDONI, A (1994): X-Rays in Ant. 1 raggi $X$ nell'arte. $2^{2}$ Edición, Roma.

GOMEZ RAMOS, P. (1995): La tecnologia de fundición de metales en la Pre y Protobistoria dela Peninsula Ibérica. Tesis Doctoral. Universidad Autónoma de Madricl.

GOMEZ DE SALAZAR/Soria (2000): "Degradación de materiales metálicos de naturaleza férrea Estudio de objetos de época romana del yacimiento palentino de La Olmeda", en Actas del XIII de Conservación y Restauración de Bienes Culturales, Lleida, 199-205.

GUICHEN, G. de (1990): "Objeto enterrado, objeto desenterrado", en Stanley Price, N.P., La conservación de excavaciones arqueológicas. ICCROM/ Ministerio de Cultura. $2^{2}$ Ed. Madrid, 3340.

JIMENO et al. (1999): "El utilillaje de hierro en Numancia y su información económica", en Burillo, F. (Cood.) IV Simposio sobre los celtiberos. Economía, Darocd 1997, 103-113.

LORRIO et al. (1999): "Minería y metalurgia celtibérica", en Burillo, F (Cood.) IV Simposio sobre los celtiberos. Economía, Daroca 1997, 161-180.

MOUREY, W.(1987): La consertation des antiquités métalliques. De la fouille au musée. LCRRA Draguignan.

OUAHMAN et al., (1998): "Corrosion des matériaux archéologiques en fer- cractérisation et d'chloruration par les plasmas d'hydrogène associés à la dessalation au sulfite alacalin, en Actes du Colloque de Poitiers: Les mëtaux antiques: travail et rstauration, sept. 1995, Ed. Monique Mergoil, Montagnac, 171-179.

PLÁ BALLESTER, E. (1968): "Instrumentos de trabajo ibérico en la región valenciana", Estudios de Economía Antigua de la Península lbérica. Barcelona.

PRATS, C. et al (1996) "La falcata y la beina damasquinades trobades a la tomba 53 de la necròpoli Ibèrica de la Serreta D'Alcoi. Procés de conservació-restauració y estudi tecnològic", Recerques del Museu D'Alcoi, V, 137-154.

PRATS DARDER, C. (1998): "La recuperación de la superficie original en piezas ibéricas de hierro", en Actas del XI Congreso de Conservación y Restauración de Bienes Culturales, Alicante, 327-332.

PRATS DARDER, C. (2000): "La limpieza de las piezas de hierro decoradas: tratamiento de una punta de lanza ibérica damasquinada en plata y cobre procedente de la necrópolis de El Puntal (Salinas, Alicante)", en Actas del XIII de Conservación y Restauración de Bienes Culturales, Lleida, pp. 285-294.

RAMÍREZ/DELOJO (1999): Métodos de Ensayo no Destructitos. Vol I, INTA

SANAHÚA, M.E. (1971): "Instrumental de hierro agricola e industrial de la época ibero-romana en Cataluña", Pyrenae, 7, Barcelona, pp.61-110.

ROYUELA, J.J. (1991): "Corrosión en suelos", en Corrosión y Protección metálicas $1 l$, pp.3-21 CSIC. Madrid.

TURGOOSE, S. (1982) "Post-excavation Changes in Iron Antiquities", Studies in Conservation, 27, 97-101. 
VVAA (1997): Proceedings of The International Conference on Metal Conservation. Metal 95, ICOM, Semur en Auxois, France, sept. 1995, Edt. James \& James (Science Publishers), London.

VVAA (1998): Proceedings of The International Conference on Metal Conservation. Metal 1998, ICOM, Draguignan. Edt. James \& James (Science Publishers), London.

VVAA (2001): Proceedings of The International Conference on Metal Conservation. Metal 2001, ICOM, Santiago de Chile, Chile, en prensa.

WAGNER et al., (1998): "A systematic approach to the evaluation of the corrosion load of archeological metal objetcs", en Proceedings of The International Conference on Metal Conservation. Metal 1998, ICOM, Draguignan, France, Edt. James \& James (Science Publishers), London, 80-86. 